(Physiologisches Laboratorium in Bonn.)

\title{
Ueber \\ die im thierischen Körper sich vollziehende Bildung von Zucker aus Eiweiss und Fett.
}

\author{
Zur Lehre des Diabetes mellitus.
}

(Eine Antwort an meine Gegner in Berlin und an Herrn Professor Dr. Hugo L üthje in Tübingen.)

Von

\section{Eduard Pflüger.}

In halt.

Seite

\$ 1. Ueber die Beurtheilung der Zuckerbildung vom Standpunkte der Structurchemie . . . . . . . . . . . . . . 1

\$2. Allgemeine Beurtheilung der fehlerhaften Beweisfihrung

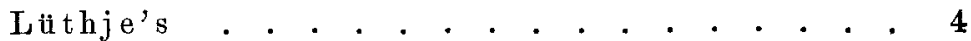

$\S 3$. Beweis der Fehlerhaftigkeit jedes einzelnen Versuches, durch den Lüthje die Zuckerbildung aus Eiweiss feststellen will. 9

$\$$ 4. Allgemeines über die Zuckerbildung aus Glycerin und über L ü thje's unrichtige Darstellung meiner Stellung zu dieser Frage . . . . . . . . . . . . . . . . 24

$\S 5$. Beurtheilung der einzelnen Glycerinversuche Lüthje's . 28

\$. Ueber die Zuckerbildung aus Fett . . . . . . . . 32

$\S 7$. Folgerungen für die Lehre vom Diabetes . . . . . . 53

\section{§ 1. Ueber die Beurtheilung der Zuckerbildung vom Standpunkte der Structurchemie.}

Nicht wenige Forscher glauben noch heute, dass die Leber viele der allerverschiedenartigsten Stoffe in Glykogen zu verwandeln vermöge. Besonders räthselhaft erscheint die angebliche Umbildung von Eiweiss zu Glykogen. Denn das Eiweissmolekül ist einem Gebäude vergleichbar, dessen einzelne Bausteine nicht aus demselben, sondern aus verschiedenem Material hergestellt sind, 
während im Gegensatz hierzu alle Bausteine des Glykogenmoleküles nicht bloss gleichartig unter sich, sondern auch von den Bausteinen des Eiweissmoleküles ganz verschieden sind.

Die Bestandtheile des Glykogenmoleküles sind Kohlehydrate, die des echten Eiweissmoleküles enthalten nicht einmal Fragmente von Kohlehydraten. Vom Serin und Tyrosin wird hier abgesehen. Weil aber die Bestandtheile des Eiweissmoleküles unter sich so sehr verschieden sind, müsste die Leber innerhalb weiter Grenzen die Fähigkeit haben, aus Stoffen fast beliebiger chemiscber Constitution immer dasselbe Glykogen herauszuarbeiten. Manche Forscher, wie z. B. der um die Lehre vom Diabetes hochverdiente v. Mering, nahmen nach Abzug des Harnstoffs den ganzen Kohlenstoff für die Zuckerbildung in Anspruch. Um Licht in diese schwer begreiflichen Räthsel zu bringen, habe ich alle in Betracht kommenden Untersuchungen kritisch bearbeitet und gelangte in meiner Monographie ${ }^{1}$ ) des Glykogens zu dem Ergebniss, dass die Entstehung von Glykogen aus Eiweiss nicht bewiesen ist. Ich zeigte, dass die bisherige Annahme der Entstehung von Kohlehydrat aus Eiweiss ihren Grund nur in Versuchsfehlern und daraus gezogenen falschen Schlussfolgerungen hat. Ich sagte in meiner Monographie des Glykogenes ${ }^{2}$ ):

"Ich habe die Hoffnung darzulegen, dass wahrscheinlich das Glykogen nur aus Kohlehydraten oder diesen sehr nahe verwandten Stoffen sich bilden kann."

Es war mir möglich zu zeigen, dass bei allen bekannten Versuchen die grosse Zuckerausscheidung der Diabetiker aus dem präformirten Glykogen des Organismus sich erklärt.

Was mich in meiner Ansicht weiter bestärkte, war die sicher gestellte und allgemein anerkannte Thatsache, dass die Leber noch nicht einmal aus allen Kohlehydraten Glykogen bereiten kann. Denn Rohrzucker und Milchzucker gehen, in's Blut gespritzt, un b enutzt von der Leber vollständig in den Harn über. Rohrzucker und Milchzueker enthalten Dextrose und Lävulose, aus denen die Leber leicht Glykogen bereitet. (Die im Milchzucker steckende Galaktose ist als Glykogenbildner noch nicht ganz sicher gestellt.) Es wäre nur nöthig, dass die Leber den Rohrzucker und Milchzucker hydro-

1) Dieses Archiv Bd. 96 S. 1.

2) Dieses Archiv Bd. 96 S. 169. 
lytisch spaltet; um ihn in Glykogen umprägen zu können. Die Leber hat aber diese Fähigkeit nicht. Das ist schwer zu verstehen, wenn man an die vielseitigen Fähigkeiten glaubt, welche die Leber haben müsste, um aus den so verschiedenen Spaltungsproducten des Eiweissmoleküles Glykogen synthetisch aufzubauen. Wie begrenzt in Wahrheit diese Fähigkeiten sind, erhellt ja noch dadurch, dass die Pentosen, obwohl sie echte Kohlehydrate sind, ebenfalls keineswegs von der Leber in Glykogen übergeführt werden können.

Nachdem also von mir bewiesen war, dass eine Berechtigung zur Annahme so vieler widerspruchsvoller Räthsel, vor allem der Verwandlung von Eiweiss in Kohlehydrat, nicht mehr vorhanden sei, hätte man glauben sollen, dass nunmehr auch ausserhalb meines Laboratoriums sich Forseher finden würden, welche bemüht wären, mir beizustehen, um die noch vorhandenen Schwierigkeiten vollkommen zu beseitigen. Das war aber nicht allein nicht der Fall, sondern es erhob sich gegen mich eine Reihe von Arbeiten, in denen doch das Eiweiss oder Bruchstücke desselben, wie z. B. Leucin und Alanin, wieder als Quelle des Glykogenes festgestellt werden sollten.

Ich erblicke darin ein Vermächtniss der Arbeiten von Carl Voit und Max Pettenkofer. Bald zerfällt nach der Meinung dieser Forscher das Eiweiss in Harnstoff und Fett, bald in Harnstoff und Zucker. Bei der Fettmästung der Thiere sollte nach Voit's Lehre das Mastfett nicht aus Koblebydrat, sondern aus Eiweiss entstehen. Wie viel Kampf und Arbeit hat es mich gekostet, um allgemein diese Irrlehre der Verwandlung von Eiweiss in Fett zu widerlegen. Ganz hat Carl Voit und sein Anhang besonders unter den Klinikern den Lehrsatz noch nicht aufgegeben, indem sie nunmehr die Möglichkeit einer indirecten Entstehung des Fettes aus Eiweiss verfechten. Denn wenn nach Carl Voit's Lehre aus Eiweiss sich Kohlehydrat bilden kann, so ist, weil aus Kohlehydrat Fett entsteht, die wenigstens mittelbare Fettbildung aus Eiweiss bewiesen.

Dabei behaupten dieselben Forscher, dass Fett und Kohlehydrate, nicht aber das Eiweiss die eigentliche Quelle der Muskelkraft seien, obwohl nach ihnen das Eiweiss fortwährend im Stoffwechsel Fett und Kohlehydrat liefert. 


\section{§ 2. Allgemeine Beurtheilung der fehlerhaften Beweisführung Lüth je's.}

Die neuesten grösseren Arbeiten zur Erbärtung der Verwandlung von Eiweiss in Zucker führen uns wieder in das Lager der Schüler Voit's. Professor Hugo Lüthje, mit dem ich mich hier ganz besonders auseinandersetzen muss, begann seine einschlägigen Arbeiten ${ }^{1}$ ) als Assistent von Professor Moritz in Greifswald, der ein naher Schüler Voit's ist.

Die neueste Hauptarbeit Lüthje's, „die Zuckerbildung aus Eiweiss", (von 1904) enthält den Satz:

"Es sei mir gestattet, aus meinen Versuchen an „pankreaslosen Tieren einige mitzutheilen, die nach "meiner Ansicht dieZuckerbildung aus Eiweiss sicher "beweisen."

An Bestimmtheit lässt diese Erklärung Lüthje's nichts zu wünschen übrig. Ich werde zeigen, dass ihr gleichwohl jede Berechtigung fehlt.

Um das Wesentliche hier sofort festzustellen, muss ich eine Darlegung zurückweisen, die Lüthje gleich beim Beginn seiner Abbandlung hervorhebt. Er sagt ${ }^{2}$ ):

„Es lässt sich übrigens meines Erachtens darüber streiten, ob "man nicht die z. B. nach Verfütterung von Ovalbumin auftretende "Zuckerausscheidung auch dann, wenn der dabei auftretende Zucker "lediglich der Kohlehydratgruppe des Ovalbumins entspringt, als das „Product einer Zuckerbildung aus Eiweiss bezeichnen darf. Wenigstens "war in der klinischen Literatur dieser Sprachgebrauch durchaus "gang und gäbe. Schliesslich sind doch eine Reihe von N-Spaltungs"producten, welche gelegentlich im Harn auftreten, wie z. B. Leucin „und Tyrosin, wie der Kohlehydratkomplex präformirt im Eiweiss"molekül enthalten, so dass man mit demselben Rechte ihre Bildungs"möglichkeit aus Eiweiss bestreiten könnte, wie diejenige des nach "Genuss von Eiweisskörpern auftretenden Zuckers."

Die Fehler in Lüthje's Betrachtung liegen in der Verkennung der Thatsache, dass Leucin und Tyrosin wesentliche, also nie fehlende Bestandtheile des Eiweissmoleküles darstellen.

1) Dr. H. Lüthje, Zur Frage der Zuckerbildung im thierischen Organismus. Münch. medic. Wochenschr. 1902 Nr. 39 S. 1601.

2) H. Lüt bje, Dentsches Arch. f. klin. Med. Bd. 79 S. 499.1904. 
Der Zucker ist aber kein wesentlicher Bestandtheil des Eiweissmoleküles. Denn gewisse Eiweissarten, wie z. B. das Caseïn, enthalten keinen Zucker. Manche Eiweissstoffe gehen mit Zucker chemische Verbindungen ein und bilden die sogenannten Glykoproteïde. Wenn sie durch Hydrolyse gespalten werden, so entstehen neben Zucker wieder echte Eiweisskörper. Dass dieser abgespaltene Zucker im Stoffwechsel wie jedes Kohlehydrat in Betracht kommt, ist ja selbstverständlich. Die Streitfrage dreht sich darum, ob das eigentliche Eiweissmolekül, welches keine Koblehydratgruppe enthält, dennoch Zucker zu liefern im Stande ist. Um dies zu beweisen, hat ja Lüthje ausgedebnte Versuche mit Caseïnnatrium, der sogenannten Nutrose, ausgeführt, die ich nachher besprechen werde.

Indem ich zur Beurtheilung von Lüthje's Versuchen übergehe, muss ich zuerst über die nicht unbeabsichtigte Fehlerhaftigkeit seiner Berechnungen berichten.

Alle Beweisführung in L üthje's Versuchen läuft darauf hinaus, zu untersuchen, ob die Zuckermengen, welche ein diabetischer Hund ausscheidet, aus dem Glykogengehalt des Thieres erklärbar sind. Um diesen Gehalt zu finden, rechnet er auf 1 Kilo Thier bald $11 \mathrm{~g}$, bald $40 \mathrm{~g}$ Glykogen. Es kommt Lüthje darauf an nachzuweisen, dass der Glykogengebalt zu klein ist, um den ausgeschiedenen Zucker zu erklären. Wenn der Factor 40 einen aus-

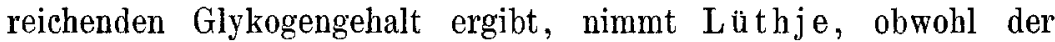
Factor 40 allein berechtigt ist, den viel kleineren Factor 11, um ein Deficit zu erhalten. Ausser einem einzigen Versuche leiden alle an diesem Fehler. Da dieses Verfahren fast unglaublich klingt, muss ich dem Leser aus einander setzen, was es mit den zwei Factoren 11 und 40 für eine Bewandtniss hat.

Als ich in meiner Monographie des Glykogenes das Capitel der Zuckerbildung aus Eiweiss zu behandeln und v. Mering's Versuche über Phloridzindiabetes zu beurtheilen hatte, sagte ich ${ }^{1}$ ):

"Wenn man einem Hunde, der keine Nahrung mehr erbält, "wiederholte Dosen von Phloridzin eingibt und die Zuckermengen, "die er durch den Harn ausscheidet, bestimmt, so hängt die wesent"lichste Schlussfolgerung davon $a b$, wie viel Glykogen der Hund nvor der Einnahme des Phloridzins in seinem Körper gehabt haben

1) Dieses Archiv Bd. 96 S. 268. 
„kann. Hier tritt dann nun gleich die erstaunliche Thatsache auf, "dass keine Versuche vorliegen, welche eine Grundlage geben zur "Beurtheilung, wie viel Glykogen in dem Körper eines reichlich er"nährten Hundes vorhanden sein kann. v. Mering ${ }^{1}$ ) hat desshalb "als Nothbehelf sich bezogen auf die Bestimmungen von $\mathrm{B} o \mathrm{hm}$ und „F. A. Hoffmann ${ }^{2}$, welche den Glykogengehalt des Gesammt„körpers der Katze zu 1,5 bis $8,5 \mathrm{~g}$ pro Kilo Thier festsetzten. "v. Mering rechnet desshalb als Maximalwert pro Kilo Hund $8,5 \mathrm{~g}$ "Glykogen. Er zieht dabei aber nicht in Betracht, dass die Ver„suche von $\mathrm{Böhm}$ und $\mathrm{H}$ offmann im Jahre 1878 angestellt sind "und das Glykogen nur durch siedendes Wasser aus den Organen "ausgezogen worden ist. Dabei erhält man, wie R. Külz ${ }^{3}$ ) be"wiesen hat, nur ungefähr $3 / 4$ des vorhandenen Glykogenes. Der "Rest kann nur durch Aufschliessen mit siedender Kalilauge er„halten werden. Demgemäss würde der Maximalwerth $8,5 \mathrm{zu}$ corrí„giren sein zu 11,3 g pro Kilo Thier. Wir wollen, weil die Rechnung "sehr erleichert wird, $11 \mathrm{~g}$ rechnen."

"Dass höhere Werthe vorkommen, ist sicher. Denn ich habe „bei Fröschen, die ich im März untersuchte, nachdem sie während "vieler Monate keine Nahrung zu sich genommen hatten, auf $1 \mathrm{~kg}$ "Thier ca. $10 \mathrm{~g}$ Glykogen gefunden."

„Das Pferdefleisch enthält sehr gewöhnlich $2 \%$ Glykogen und „auch mehr. Rechnet man $40 \%$ des Thiergewichts auf Fleisch, so "würden auf $1 \mathrm{~kg}$ Thier $8 \mathrm{~g}$ Glykogen in den Muskeln kommen. „Da nun bei gutem Ernährungszustand die Leber ungefähr ebenso„viel Glykogen als die Muskulatur enthält, so würden $16 \mathrm{~g}$ Glykogen "für Leber und Muskeln pro Kilogramm Pferd zu rechnen sein."

"Wir sind beute in der Lage, für die gerade beim Hunde "möglichen Maximalwerthe des Glykogengehaltes des ganzen Thieres "ein ziemlich sicheres Urtheil zu bilden. F. W. $\mathrm{Pavy}^{4}$ ) bestimmte, "dass ein Hund bei gemischter, an Koblehydraten reicher Nahrung „in der Leber bis $12 \%$ Glykogen aufweist, und dass die Leber

1) v. Mering, Zeitschr. f. klin. Med. Bd. 16 S. 437. 1889.

2) R. Böhm und F. A. Hoffmann, Arch. f. exper. Pathol. u. Pharmak. Bd. 8 S. $271 \mathrm{ff}$. und S. $375 \mathrm{ff}$.

3) Richard Külz, Zeitschr. f. Biol. Bd. 22 S. 194. 1886.

4) F. W. Pavy, The Physiology of the Carbobydrates p. 114. 1894. 
Ueb. die im thier. Körper sich vollziehende Bildung von Zucker etc.

„dann $6,6 \%$ des Körpergewichts ausmacht. Daraus folgt, dass ${ }_{n} 1 \mathrm{~kg}$ Hund 7,92 g Leberglykogen

„enthält; weil nun durchschnittlich im Körper wohlgenährter Thiere "mindestens ebensoviel Glykogen als in der Leber sich findet, "würde sich ergeben als Gesammtglyliogen

\section{$15,8 \mathrm{~g} \cdot{ }^{\prime \prime}$}

"Es sei ferner darauf hingewiesen, dass Erwin Voit ${ }^{1}$ ), der „eine Gans mästete und dann das Gesammtglykogen des Thieres „nach Brücke feststellte, fand:

$$
1 \mathrm{~kg} \text { Gans }=22,2 \mathrm{~g} \text { Glykogen. }
$$

„Wenn ich also für den Hund rechne

$$
1 \mathrm{~kg} \text { Hund }=11 \mathrm{~g} \text { Glykogen, }
$$

"so befinde ich mich sicher unter dem möglichen Maximalwerthe."

Wie man sieht, war ich bei Beurtheilung der Versuche v. Mering's in einer Nothlage. Ich musste wissen, wie viel Glykogen wohl in dem Körper eines Hundes enthalten sein kann. Nicht eine einzige Untersuchung lag zur Beantwortung dieser Frage vor. Ich musste mit v. Mering mich auf ungenügende alte Versuche an Katzen stützen und gelangte so zu 11 g Glykogen pro 1 Kilo Thier. Eine wesentliche Stütze erwuchs mir aus F. W. Pavy's Versuchen, der Hunde auf Glykogen gemästet, aber nur den Gebalt derselben in der Leber bestimmt hatte. So konnte ich ungefähr die Gesammtmenge des Glykogenes im ganzen Körper des Hundes schätzen und die Gewissheit erlangen, dass der von mir angewandte Werth von $11 \mathrm{~g}$ Glykogen als Maximalzahl pro 1 Kilo gemästeter Hund nicht zu hoch gegriffen, ja sicher zu niedrig sei.

Wie weit aber diese von mir als Maximalwerth benutzte Zahl unter dem wirklichen Maximum liege, blieb unbekannt. Es war mir desshalb angenehm, als Prof. B. Schöndorff mir den Wunsch aussprach, durch eine umfassende Untersuchung die empfindliche Lücke unserer Kenntnisse auszufüllen. Ich war täglicher Zeuge von Schöndorff's Untersuchungen und weiss, dass die von ihm noch im vorigen Jahr nach meiner Monographie veröffentlichten Ergebnisse richtig sind. So wurde festgestellt:

"1 kg Hund kann bei reichlicher Ernährung mit Fleisch und "Kohlehydraten in maximo $40,897 \mathrm{~g}$ Zucker, resp. 37,87 g Glykogen "enthalten" 2 ).

1) Erwin Voit, Zeitschr. f. Biol. Bd. 25 S. 543.

2) Dieses Archiv Bd. 99 S. 220. 
Um die grosse Bedeutung dieses hohen Werthes herabzusetzen, macht $L$ ü thje die wahrheitswidrige Angabe ${ }^{1}$ ), dass „ein solcher "Werth bisher überhaupt nur einmal bei besonders "präparirten Thieren gefunden worden ist".

Schöndorff hat 7 Versuche angestellt und bei 4 Hunden, also der Hälfte der Thiere, so ausserordentlich hohe Werthe pro 1 Kilo gefunden: wie 19,72, 32,49, 37,64, 40,897 g Zucker.

Zur besseren Uebersicht gebe ich Schöndorff's Tabelle ${ }^{2}$ ):

$1 \mathrm{~kg}$ Thier enthielt:

\begin{tabular}{c|c|c}
\hline \hline Versuch & Zucker in $\mathrm{g}$ & Glykogen in $\mathrm{g}$ \\
\hline 1 & 6,23 & 5,78 \\
2 & 7,75 & 7,18 \\
3 & 32,49 & 30,07 \\
4 & 40,897 & 37,87 \\
5 & 37,64 & 34,89 \\
6 & 19,72 & 18,28 \\
7 & 8,19 & 7,59
\end{tabular}

Die wahrheitswidrige Angabe Lüthje's kann man eigentlich nur begreifen, wenn man annimmt, dass er Schöndorff's Arbeit nicht gelesen hat. Erstaunlich erscheint aber, dass bei gleicher Fütterungsart so ungeheure Unterschiede im Glykogengehalte des Körpers vorkommen. Sicher aber ist, dass der Maximalwerth des im ganzen Körper eines Hundes enthaltenen Glykogenes pro Kilo $37,87=40,897 \mathrm{~g}$ Zucker betragen kann.

In Ergänzung von Schöndorff's Zahlen kann ich darauf hinweisen, dass Madame Gatin-Gružewska ${ }^{3}$ ) in meinem Laboratorium auch 3 Hunde auf Glykogen gemästet und bei zweien dieser Thiere die ungeheuren Werthe von $18,88 \%$ und $19,89 \%$ durch Inversion aus Glykogen erhaltenen Zucker für die Leber festgestellt hat. Da nun der Gesammtgehalt des Körpers ungefähr das Doppelte beträgt, so würden die beiden Hunde pro Kilo $37,8 \%$ und $40 \%$ Zucker liefern können.

Die Einrede Lüthje's, dass Schöndorff's Maximalwerth nur ein einziges Mal beobachtet sei, ist also ganz unberechtigt.

1) H. Lüthje, Deutsches Arch. f. klin. Med. Bd. 79 S. 512.1904.

2) B. Schöndorff, dieses Arch. Bd. 99 S. 213. 1903.

3) Madame Gatin-Gružewska, dieses Archiv Bd. 102 S. 569. 
Bei der Beurtheilung der Verhältnisse des Menschen bleibt aber zu beachten, dass wir gar nichts über den maximalen Glykogengehalt desselben wissen, so dass die Anwendung der bei Thieren erhaltenen Zahlen immer mit einer gewissen Unsicherheit behaftet ist.

Wenn in der 1904 veröffentlichten Arbeit von Lüthje der Maximalwerth des Glykogenes pro 1 Kilo Hund in die Rechnung einzusetzen ist, musste die Zahl $40 \mathrm{~g}$ Zucker (eigentlich rund $41 \mathrm{~g}$ ) eingesetzt werden. Weil aber die Verwendung dieser Zahl fast alle Versuche Lüthje's ibrer Beweiskraft entkleidet haben würde, benutzte Lüthje die nicht mehr berechtigte Zahl $11 \mathrm{~g}$ Glykogen pro Kilo Hund als Maximalwerth. Nur bei einem einzigen Versuche benutzt er Schöndorff's Zahl 40, weil hier ein ausserordentlich hoher Zuckergehalt auftritt, welcher auch bei Anwendung der Zahl 40 durch das Gesammtglykogen des Körpers nicht gedeckt ist. Ich werde die Bedeutung auch dieses, eine Ausnahme darstellenden Versuches eingehend besprechen.

Da Lüthje im Tone der überlegensten Ueberzeugung seine Lehren vorträgt, so werde ich mich wohl mit diesen allgemeinen Darlegungen nicht begnügen dürfen. Auf die Einzelheiten muss ich eingehen, um dem Leser die sichere Ueberzeugung von den Irrthümern Lüthje's zu verschaffen.

\section{$\S 3$. Beweis der Fehlerhaftigkeit jedes einzelnen Versuches,} durch den Lïthje die Zuckerbildnng aus Eiweiss feststellen will.

$$
\text { Lüthje's Versuch I }{ }^{1} \text { ). }
$$

Hund von $15150 \mathrm{~g}$ hungert vom 14. April bis 2. Mai - also 18 Tage.

Da ich bei einem Hunde, der 28 Tage gehungert hatte, in der Leber noch 4,3\% Glykogen fand, konnte dieser Hund Lüthje's noch sehr erbebliche Mengen Glykogen in seinem Körper beherbergen ${ }^{2}$ ).

Nach der Hungerzeit von 18 Tagen wird dem Hund als Vorbereitung für den eigentlichen Versuch Nahrung, "vorwiegend Fleisch", gereicht, so dass vom 3. bis 28. Mai, also in 25 Tagen, das Gewicht des Hundes von $10505 \mathrm{~g}$ auf $13000 \mathrm{~g}$ steigt. Der Hund ist folglich

1) Lü thje, Dentsches Arch. f. klin. Med. Bd. 79 S. 500. 1904.

2) E. Pflùg er, dieses Arch. Bd. 96 S. 168. 1903. 
reichlich mit gemischter Nahrung, also doch wohl auch mit Kohlehydraten gefüttert worden. Nun zeigen die Versuche Schöndorff's ${ }^{1}$ ), dass nach einer längeren vorausgegangenen Hungerzeit die Zufuhr von Kohlehydraten ganz ungeheure Ablagerungen von Glykogen in allen Organen besonders begünstigt. Lüthje irrt desshalb, wenn er sagt $\left.{ }^{2}\right)$ : „Der Hund hatte also an dem Operationstage „sein Anfangsgewicht vom 14. April noch lange nicht wieder er„reicht; man darf daher vielleicht annehmen, dass er nicht besonders "glykogenreich war." Nein! Das darf man nicht annehmen. Es kommt ja gar nicht darauf an, um wieviel der Hund in der Hungerperiode an Gewicht abnahm. Das Wesentliche liegt daran, um wieviel er nach der Hungerperiode bei reichlicher Nahrung zugenommen hat, und da handelt es sich um den grossen Betrag von $2500 \mathrm{~g}$, von denen das aufgestapelte Glykogen einen unbekannten Theil ausmacht. Wir dürfen demnach in diesem Falle Glykogenmästung annehmen.

Nachdem die Ausrottung des Pankreas am 28. Mai vollzogen worden war, bekam der Hund nichts mehr zu fressen bis zum 22. Juni - also während 26 Tagen; während dieser Zeit wurde seine gesammte Zucker- und Stickstoffausscheidung bestimmt.

Der Hund schied 200,9 $\mathrm{g}$ Zucker in diesen 26 Tagen aus. Wie viel Glykogen konnte der Hund nun am Tage der Operation noch in seinem Körper beherbergen. Da nimmt Lüthje pro Kilo Hund $11 \mathrm{~g}$ an. Für das Gewicht des Hundes setzt er $12000 \mathrm{~g}$, so dass das Thier $131 \mathrm{~g}$ Glykogen $=145 \mathrm{~g}$ Zucker noch in sich enthalten konnte.

Wenn Lüthje hier als Maximalwerth $11 \mathrm{~g}$ Glykogen pro Kilo Hund rechnet, so habe ieh vorher dargelegt, wesshalb Lü thje zur Annahme dieser niedrigen Zahl nicht mehr berechtigt war.

Benutzen wir den berechtigten Maximalwerth in runder Summe pro 1 Kilo Hund $41 \mathrm{~g}$ Zucker, so würden 12 Kilo $492 \mathrm{~g}$ Zucker liefern können, also fast noch ein Mal soviel, als das Thier in 26 Tagen ausschied.

Weil Lüthje die als Maximalwerth nicht mehr berechtigte Zahl 11 g Glykogen pro Kilo Hund anwendet, findet er, dass das Thier

1) B. Schöndorff, dieses Archiv Bd. 99 S. 191.

2) Lüthje, Deutsches Arch. f. klin. Med. Bd. 79 S. 500. 
„rund $56 \mathrm{~g}$ mehr, als dem supponirtem Glykogengehalt entsprechen "würden", ausgeschieden hat. Scheinbar befriedigt fragt er:

"Woher stammt dieser überschüssige Zucker?"

Nach Obigem heisst in Lüthje's Sinn die Antwort:

"Hier ist die Entziehung von Zucker aus Eiweiss sicher be"wiesen."

Nein! Hier liegt eine unberechtigte Rechnung vor.

Lüthje's Versuch II ${ }^{\mathbf{1}}$ ).

Einem Hunde von $9000 \mathrm{~g}$ wird am 3. Januar das Pankreas exstirpirt. Welche Ernährung vor der Operation stattgefunden hatte, ist nicht angegeben. Nach der Operation wurde der Hund theils mit Milch, theils mit Fleisch, aber ungenügend ernährt; vom 12. bis 15. Janiar bekam der Hund pro Tag 250 g Fleisch als Vorbereitung zu der am 15. Januar ausgeführten Entfernung das Pankreas. Die Beobachtung des Thieres währte bis zum 9. Februar, also 25 Tage. Die gesammte Zuckerausscheidung beläuft sich nach Lüthje auf $1271,3 \mathrm{~g}$.

Der Hund hatte während der 25 Beobachtungstage $16500 \mathrm{~g}$ mageres Pferdefleisch als Nahrung erhalten. Wie viel Glykogen in diesem Fleische war, bestimmt Lüthje nicht, sondern nimmt $3 \%$ an, da, wie Lüthje sagt, nach Pflüger das Pferdefleisch $1-2 \%$ Glykogen entbält. Lüthje hat nun bei dieser bequemen Art der quantitativen Analyse nicht bedacht, dass meine Angaben sich auf das Fleisch der in Bonn geschlachteten Pferde beziehen, und dass der Glykogengehalt in dem Körper der Thiere ganz ungeheuren Schwankungen je nach den verschiedenen Lebensbedingungen unterliegt. Ich hätte es nie für möglich gehalten, dass unter Umständen das Fleisch der Hunde 3,72\% Glykogen $=4,01 \%$ Zucker enthalten kann. Als B. Schöndorffí) dies in meinem Laboratorium fand, sagte ich ihm, dass das Niemand glauben werde, wenn er nicht durch sehr viele Versuche und garantirte Analysen die Thatsache durchaus sicher stelle. Nun ist es mir immer aufgefallen, dass die Kutscher im Schwarzwald und in der Schweiz die den Wagen ziehenden Pferde noch im Trabe gehen lassen, wo recht bedeutende Steigungen sich finden. In Bonn geht das Pferd der

1) Lüthje, Deutsches Arch. f. klin. Med. Bd. 79 S. 502 ff.

2) B. Schöndorff, Bd. 99 S. 221. 1903. 
öffentlichen Fubrwerke bei der geringsten Steigung sogleich nur im Schritt. Ich glaube desshalb, dass die Güte der Ernährung der Pferde in verschiedenen Gegenden recht erhebliche Unterschiede darbietet. Wenn also sogar das Hundefleisch in maximo $4 \%$ Zucker liefert, so ist es wohl denkbar, dass das Fleisch des Pferdes, welches unter allen Thieren den grössten Glykogenreichthum der Muskeln aufweist, bei reicher Ernährung noch viel mehr Glykogen im Fleisch, als ein Hund beherbergen kann.

Wie merkwürdig sich das Pferd in dieser Beziehung verhält, ersieht man z. B. aus den Beobachtungen von D. Gustav Alde$\mathrm{h}$ off $\mathrm{f}^{1}$ ), welcher bei einem gesunden Pferde im M. glutaeus maximus, nachdem es $9 \mathrm{~T}$ age gehungert latte, noch 2,4386\% Glykogen $=2,71 \%$ Zucker nachweisen konnte. Es ist also sehr wohl denkbar, dass in $16500 \mathrm{~g}$ des von Lüthj e gefütterten Fleisches genügend Glykogen vorhanden war, um im Verein mit dem im Hund selbst noch vorräthigen Glykogen die gesammte Zuckermenge zu erklären, welche sein diabetischer Hund ausschied. Da Lü thje keine Analyse gemacht hat, um diesen wichtigen Punkt sicher zu stellen, beweist der Versuch nichts.

\section{Lüthje's Versuch III.}

Einem grossen, gut genährten Hund wird am 19. Juli das Pankreas exstirpirt und das Thier dann nicht mehr, bis zum 11. August, gefüttert. - In einer 14 tägigen Hungerperiode scheidet der Hund aus 472,36 g Zucker.

Da der Hund bei Beginn des Versuches $16,3 \mathrm{~kg}$ wog und 1 Kilo in maximo $41 \mathrm{~g}$ Zucker liefern kann, so ergeben sich

$$
16,3 \times 41=668,30 \mathrm{~g} \text { Zucker. }
$$

Der von dem Thier ausgeschiedene Zucker ist also durchaus mehr als gedeckt. Lüthje aber rechnet als Maximalwerth des Glykogenes auf 1 Kilo Thier den alten, niedrigen Werth von $11 \mathrm{~g}$, welcher durch die beweiskräftigen Versuche Schöndorff's als zu klein sichergestellt ist.

Der Versuch III Lüthje's ist also ebenso werthlos wie die früheren Versuche.

1) G. A Idehoff, Zeitschr. f. Biol. Bd. 25 S. 147 und E. Pflüger, dieses Arch. Bd. 96 S. 158. 


\section{Lüthje's Versuch IV.}

Die Beurtheilung dieses Versuches ist dadurch eigentlich unmöglich gemacht, dass $\mathrm{L} u ̈$ thje offenbar falsche Angaben über die Zeit gemacht hat, wo die Totalexstirpation des Pankreas des Hundes stattgefunden hat. Das soll am 2. Februar geschehen sein. Nun wird über das Verhalten des Thieres im ganzen Februar kein Wort gesagt und erst vom 3. März hebt der Bericht an. Es ist also wohl unzweifelhaft, dass die Operation der Exstirpation des Pankreas nicht am „2. Februar", sondern am 2. März stattgefunden hat. Denn vom 3. März ab gibt Tabelle IV ${ }^{1}$ ) Auskunft tiber die ganze Beobachtungszeit vom 3 . bis 25 . März.

Ich habe nun ermittelt, dass dieser jetzt 1904 veröffentlichte Versuch schon einmal von ibm 1902 in Nr. 39 der Münchener Medicinischen Wochenschrift veröffentlicht ist und noch in Greifswald ausgeführt wurde, wobei Dr. Eden die Totalexstirpation des Pankreas vollzog. Das Alles verschweigt Lüthje nicht bloss bei diesem, sondern auch bei anderen Versuchen. Aus der früheren Veröffentlichung folgt nun, dass in der That die Totalexstirpation des Pankreas am 2. März stattgefunden hat.

Das Thier, welches nach der Operation erkrankt war, erhielt nun vom 3. bis 15. März Pferdefleisch und Milch in nicht ganz genau bestimmten Mengen. Man weiss also nicht sicher, wie viel von den 248,72 g Zucker dieser Periode durch die Kohlehydrate der Nahrung gedeckt sind. Es ist desshalb möglich, dass ein noch erheblicher Gehalt von Glykogen am Schlusse dieser Periode im Thiere vorhanden war.

Vom 15. März bis zum 21. März hungert das Thier, sondert keinen Zucker ab und erhält vom 21. bis 24. März, also 4 Tage hinter einander, je $60 \mathrm{~g}$ Nutrose und entleert im Ganzen $57 \mathrm{~g}$ Zucker.

Da der Hund am Anfange des Versuchs $6909 \mathrm{~g}$ wog, konnte er $6,909 \times 41=283,3 \mathrm{~g}$ Zucker aus Glykogen liefern. Wäbrend der ersten 2 Wochen wurde er mit Fleisch und Milch gefüttert und hatte also seinen Glykogenvorrath nur theilweise eingebüsst. Wenn er bei der Nutrose-Fütterung dann noch $57 \mathrm{~g}$ Zucker entleerte, so ist diese Menge, ja noch viel mehr, durchaus gedeckt. Der Versuch beweist also nichts.

1) Lüthje, Deutsches Arch. f. klin. Med. Bd. 79 S. 505. 
Wenn hier die Zufuhr von Nutrose eine Vergrösserung der Zuckerausscheidung zur Folge hatte, so darf man daraus nicht mit Lüthje schliessen, dass der Zucker aus der Nutrose entstanden ist. Denn Zufuhr von Ammoniak soll ja die Glykogenmenge der Leber vergrössern und doch denkt Niemand, dass das Glykogen aus Ammoniak entstanden ist. - Es handelt sich bier um indirecte Beziehungen.

Nach Erledigung seines Versuches IV hält mir Lüthje noch einen Versuch von $K \ddot{u} \mathrm{l}^{1}{ }^{1}$ ) vor, welcher die Zuckerbildung aus Eiweiss, speciell aus einem Eiweisskörper ohne Kohlehydratcomplex, darthun soll.

Es handelt sich um einen 27 jährigen Mann mit schwerem Diabetes. $\mathrm{K} \ddot{u} 1 \mathrm{z}$ stellte 2 Versuchsreihen an. In der ersten Versuchsreihe, welche 4 Tage dauerte, erhielt der Kranke täglich 200 bis $500 \mathrm{~g}$ Casein und schied im Ganzen $364,6 \mathrm{~g}$ Zucker aus. Da der Kranke nur am 4. Versuchstag, sonst nicht, überwacht wurde, hat der Versuch keinen Werth.

Die zweite Versuchsreihe und ihre Ergebnisse ersieht man aus folgender Tabelle.

\begin{tabular}{l|c|c|c|c}
\hline \hline Datum & $\begin{array}{c}\text { 24 stündige } \\
\text { Urinmenge } \\
\text { ccm }\end{array}$ & $\begin{array}{c}\text { Menge des in } \\
\text { 24 St. verab- } \\
\text { reichtenCaseïn } \\
\text { g }\end{array}$ & $\begin{array}{c}\text { Zucker in } \\
\text { \% }\end{array}$ & $\begin{array}{c}\text { Menge des } \\
\text { aus- } \\
\text { geschiedenen } \\
\text { Zuckers }\end{array}$ \\
\hline 19. März & 4100 & 200 & 1,48 & 66,0 \\
20. & 6140 & 240 & 1,07 & 65,7 \\
$21 . \quad "$ & 6620 & 300 & 1,46 & 96,7 \\
$22 . \quad "$ & 7210 & 500 & 1,76 & 126,9 \\
23. & 5250 & 240 & 1,65 & 86,6 \\
\hline
\end{tabular}

Summe 441,9

Bei dieser Versuchsreihe wurde der Kranke 5 Tage und 5 Nächte überwacht. Was er aber vor der Versuchsreihe gegessen hat, wo er nicht überwacht wurde, beruht nur auf dem guten Glauben von E. Külz, dass der Patient die vorschriftsmässige kohlehydratfreie Nahrung allein zu sich genommen habe. E. K ülz beweist selbst durch die Ueberwachung der während der 5 Tage durchgeführten Caseïnfütterung, dass ohne Ueberwachung eine Sicherheit nicht vorhanden war. Es sind demnach dem Patienten vor der Caseïnperiode mög-

1) E. Külz, Arch. f. exper. Pathol. u. Pharmak. Bd. 6 S. 140. 
licher Weise grosse Mengen von Kohlehydraten zugeführt worden. Wenn dann der Patient in 5 Tagen $441,9 \mathrm{~g}$ Zucker ausschied, so erklären sich diese leicht aus dem vorhandenen Bestand an Kohlehydraten, denn ein erwachsener Menseh von 50 Kilo kann $2000 \mathrm{~g}$ Glykogen enthalten. Dabei bleibt zu beachten, dass doch bis heute nicht ein einziger Versuch vorliegt, welcher uns einen Begriff gibt, wie hoch sich bei einem gut genährten Menschen der Gehalt an Glykogen wohl belaufen kann. Gerade so wie man bis jetzt bei dem Diabetes der Hunde ohne Bedenken schloss, dass der ausgeschiedene Zucker nicht durch den Glykogenvorrath des Körpers gedeckt sei, obwohl man die Grösse desselben gar nicht kannte, genau so verhält es sich bei dem Versuche von E. Külz.

Der Versuch von E. Külz beweist also gar nichts. - Nach $L u ̈ t h \mathrm{e}^{1}$ ) wird durch diesen Versuch von $\mathrm{K} u ̈ l z$ die Zuckerbildung aus Eiweiss, „speciell aus einem Eiweisskörper ohne Kohlehydratcomplex", dargethan.

Wenn wir in diesem räthselvollen Gebiete wirkliche Fortschritte machen wollen, müssen wir auf das Strengste das Sichere vom Unsicheren scheiden und nicht zu Gunsten von Lieblingsideen der Wahrheit Zwang anthun.

\section{Lüthje's Versuch V.}

Einem Hunde von $18 \mathrm{~kg}$ wird nach 5 Hungertagen am 21. December von Herrn Prof. Küttner das Pankreas exstirpirt und dann weitere 13 Tage keine Nahrung gereicht. Vom 20. Hungertage ab erhält das Thier erst Casein, dann Nutrose während 10 Tagen. Die Zufuhr der Nutrose bedingte eine bedeutende Steigerung der Zuckerausscheidung und genügte, um das Körpergewicht während 10 Tagen constant zu halten.

Lü thje stellt das Ergebniss des Versuches zusammen in folgender Uebersicht:

In den ersten 19 Hungertagen ausgeschieden . 228,80 g Zucker, während der Fütterung mit Caseïn . . . . 975,30 ” " und weiter während der dann folgenden Hungerperiode . ..$\dot{\text { das macht insgesammt }} \cdot \frac{150,40 \%}{1354,50 \mathrm{~g} \text { Zucker. }}$

1) H. Lüthje, Deutsches Arch. f. klin. Med. Bd. 79 S. 508. 
L ü thje sagt nun:

"Der Hund wog im Anfang $18 \mathrm{~kg}$. Rechnet man den bisher "gefundenen Maximalwerth von $40 \mathrm{~g}$ Glykogen pro Kilo Hund, so "würde dieser Hund in maximo $720 \mathrm{~g}$ Glykogen enthalten haben. „Dem würden rund $800 \mathrm{~g}$ Zucker entsprechen. Es bleiben also „nngedeckt 554,40 g Zucker.“

Wenn wir die Beurtheilung dieses Versuches $V$ in das Auge fassen, so fällt zuerst auf, dafs Lü thje wiederholt in seiner Abhandlung angibt, wie er verfährt, um sich zu überzeugen, dass in dem Futter des Thieres keine Kohlehydrate sind. Da heisst es gerade bei dem Versuche V (S. 509): „Die Caseinpräparate wurden "von mir selbst auf Kohlehydrate untersucht: es fanden sich keine "reducirenden Substanzen darin." Die Worte "reducirende Substanzen" hat Lüthje gesperrt gedruckt. Bei Versuch IV sagt Lüthje abermals (S. 507) in fetter Schrift: „Dies Nutrosepräparat „enthielt nach meiner Untersuchnng keine reducirenden Sub"stanzen." Offenbar meint Lüthje: Was nicht reducirt, ist kein Kohlehydrat. Stärke und Rohrzucker reduciren nicht und sind doch entschiedene Koblehydrate und Glykogenbildner. Ob also das Nutrosepräparat wirklich frei von Kohlehydraten war, ist durch $\mathrm{L} \ddot{\mathrm{u}} \mathrm{thj}$ e nicht sichergestellt.

Wer so bedenkliche Angaben über seinen Kohlehydratnachweis macht, der wird sich nicht wundern dürfen, wenn der Leser auch von der Richtigkeit seiner Zackeranalysen keineswegs überzeugt ist. Wie ist es möglich, fragt man sich, dass ein Forscher, der so ungewöhnliche Werthe der Zuckerausscheidung beobachtet, sein Ergebniss nicht sichert, indem er den Zucker auf verschiedene Weise bestimmt. Lü thje begnügt sich mit der polarimetrischen Methode, welche an Genauigkeit der chemischen erheblich nachsteht. Aber auch hier fehlt jede Angabe, aus welcher der Leser die Ueberzeugung gewinnen kann, dass die polarimetrischen Analysen richtig sind. Lüthje arbeitete mit einem Halbschattenapparat von Schmidt \& Haensch. Gewiss liefert diese Firma ausgezeichnete Apparate. Trotzdem ist eine Prüfung nöthig, welche bezeugt, dass der Apparat fehlerlose Angaben macht. Die von Lüthje angegebenen Zuckerwerthe entbehren also der nöthigen Sicherheit - wenigstens für den Leser. Das ist um so bedenklicher, als die von ihm gefundene Zahl dann mit einem grossen Factor multiplicirt wird, um den gesammten Zuckergehalt des 24 stündigen Harns zu finden. 
Rumpf hat bei seinen Versuchen immer den Zucker nicht bloss polarimetrisch, sondern auch chemisch bestimmt. -

Um auch dem diesem Gebiete ferner Stehenden einen Begriff zu geben, wie es mit der Genauigkeit der quantitativen polarimetrischen Analysen in der Literatur in Untersuchungen steht, die nicht etwa von Schülern und Dilettanten, sondern von hochangesehenen Männern der Wissenschaft angestellt worden sind, soll sofort bewiesen werden.

Wie gross wurde die specifische Drehung des Glykogenes befunden?

Dieselbe ist zuerst in meinem Laboratorium von Madame Z. Gatin-Gružewska ${ }^{1}$ ) festgestellt zu

$$
[\alpha]_{D}=196,57^{\circ} \text { oder }[\alpha]_{j}=221,13^{\circ} .
$$

$\mathrm{Huppert}$ hat zwar genau denselben Werth bereits vor Madame Gatin-Gružewska gefunden, aber nur, weil die verschiedenen von ihm begangenen Fehler sich compensirt haben. Denn in seine Berechnungen setzt er eine unrichtige Zahl für das Molekulargewicht des Glykogenes $\left[6\left(\mathrm{C}_{6} \mathrm{H}_{10} \mathrm{O}_{5}+\mathrm{H}_{2} \mathrm{O}\right)\right]$ und ebenso eine unrichtige Zahl für die quantitative Beziehung zwischen Glykogen und Zucker, weil er den bei der Inversion unvermeidlichen, nicht unbeträchtlichen Zuckerverlust nicht berücksichtigt. Bei der Bestimmung der Drehung des Glykogenes gebraucht er verunreinigte Lösungen, weil er das Gewicht des Glykogenes indirect aus dem durch Inversion erhaltenen Zucker berechnet. Ob die unbekannte Verunreinigung eine Veränderung der specifischen Drehung des Glykogenes bewirkt, ist nicht nachgewiesen.

Madame Gatin-Gružew ska hat mit absolut reinem Glykogen gearbeitet.

Dass unser Halbschattenapparat richtige Werthe gab, folgt daraus, dass die erste Autorität auf diesem Gebiete, Herr Professor H. Landolt, den Apparat bei Schmidt \& Haensch in Berlin vor der Absendung an mich controlirt hat, und dass ich nach Aufstellung des Apparates in Bonn die specifische Drehung chemisch reinen, nach Soxhlet dargestellten Traubenzuckers bei $20^{\circ} \mathrm{C}$. bestimmt und gefunden habe

$$
[\alpha]_{D}=52,8^{\circ} .
$$

1) Madame Gatin-Gružewska, dieses Arch. Bd. 102 S. 569. 
Welche Werthe finden wir nun in der Literatur für die specifische Drehung des Glykogenes?

Uebersicht über diespecifische Drehung des Glykogenes nach Angabeverschiedener Forscher.

\begin{tabular}{c|l}
\hline $\begin{array}{c}\text { Specif. Drehung } \\
\text { ausgedrückt als } \\
{[\boldsymbol{\alpha}] j}\end{array}$ & \multicolumn{1}{c}{ Name des Forschers } \\
\hline $127,27^{\circ}$ & B. Luch sing e r \\
$168,00^{\circ}$ & Fin n \\
$211,00^{\circ}$ & E. K ül z \\
$226,70^{\circ}$ & Böhm und H offma n n \\
$221,13^{\circ}$ & Madame Gatin-Gružew ska
\end{tabular}

Die Werthe von $B o ̈ h m$ und Hoffmann und $K \ddot{u} l z$ müssten noch etwas grösser genommen werden. Diese Forscher haben zur Berechnung von $[\alpha]_{j}$ die Formel gebraucht $[\alpha]_{j}=\frac{56,4 \times \alpha}{p}$, worin 56,4 die specifische Drehung des Traubenzuckers in $[\alpha]_{j}$ ausgedrückt bedeutet. Das ist der alte Werth. Aber bereits 1881, wo $\mathrm{Külz}$ jene Arbeit veröffentlichte, war durch Tollens $[\alpha]_{D}=52,8^{\circ}$ endgültig festgestellt, entsprechend $[\alpha]_{j}=59,4^{\circ}$, nicht aber $56,4^{\circ}$. -

Vergleicht man nun den Werth von Luchsinger mit dem von $\mathrm{B} \ddot{\mathrm{h}} \mathrm{m}$ und $\mathrm{H}$ offmann, so ist das ein Unterschied von $78,1 \%$.

Wichtiger ist noch, dass derselbe Beobachter, wie z. B. Külz ${ }^{1}$ ) selbst berichtet, einmal $[\alpha]_{j}=203,0^{\circ}$, das andere Mal $[\alpha]_{j}=233,5^{\circ}$ findet. - Ganz ähnlich verhält es sich mit anderen Beobachtern. Diese sicheren Thatsachen können nicht aus der Welt geschafft werden durch die Bemerkung, dass der Saccharometer noch ${ }^{1 / 100}$ Grade abzulesen gestatte. E. $\mathrm{Külz}$ hat ja auch mit einem Halbschattenapparat von Schmidt \& Haensch gearbeitet. Fine Unsicherbeit dieser Apparate liegt noch besonders darin, dafs das angewandte gelbe Licht beim Gebrauch leicht erheblich von der Linie $D$ abweicht. Letzteres bezieht sich nicht auf $\mathrm{K} \ddot{\mathrm{llz}}$.

Da nun Lüthje seine Drehungswerthe noch oft mit 10 multiplicirt hat, so ist es gewiss, dass die Differenzen, auf die er Gewicht legt, noch in die Fehlergrenzen der polarimetrischen Methode fallen können. Da ich nicht beweisen kann, wie weit die Analysen

1) E. Külz, dieses Arch. Bd. 24 S. 87 u. 88. 1881. 
Lüthje's von dem richtigen Werthe abweichen, bleibt mir übrig, trotz Allem zu prüfen, welche Schlussfolgerungen aus dem Versuche $\mathrm{V}$ gezogen werden dürfen, wenn man die Richtigkeit der Analysen zugibt.

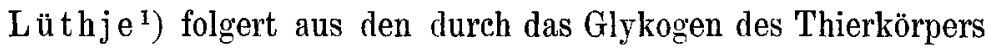
ungedeckten 554,4 g Zucker:

„Schon die absolute Grösse der Zuckerausscheidung in diesem "Versuche lässt keine andere Deutung zu, als dass hier Zucker aus „etwas Anderem entstanden sei als aus Zucker; und nach allen "unseren Erfahrungen müssen wir annehmen, dass der Zucker aus "Eiweiss gebildet ist."

Man traut seinen Augen nicht, wenn man das liest. Also weil das im Thierkörper enthalten gewesene Glykogen die Menge des ausgeschiedenen Zuckers nicht erklärt, kann nur das Eiweiss den Zucker geliefert haben. Ist denn das Glykogen das einzige Kohlehydrat? Kommt nicht noch freier Zucker und in Glykoproteiden gebundener vor? Gibt es denn Methoden, um mit Sicherheit den Betrag der Gesammtkohlenhydrate festzustellen? Wo ist eine Berechtigung herzuleiten, dass der Betrag der nehen dem Glykogen im Thierkörper enthaltenen Kohlenhydrate gleich Null gesetzt werden darf? - Aber ferner: hat nicht Lüthje gegen mich soeben in einer neuen Arbeit mit grösster Bestimm theit den Satz verfochten, dass das Glycerin eine entschiedene unmittelbare Quelle des Zuckers sei, was ich niemals grundsätzlich geleugnet habe? Nach J. König schwankt der procentische Fettgehalt eines ganzen Thieres von $14,8 \%$ bis $45,8 \%$. Ein Hund von $18 \mathrm{~kg}$ könnte also in maximo $8,2 \mathrm{~kg}$ Fett $=820 \mathrm{~g}$ Glycerin beherbergen. $820 \mathrm{~g}$ Glycerin würden fast ebensoviel Zucker zu liefern im Stande sein. Es handelt sich hier um die Erklärung von $554,4 \mathrm{~g}$ Zucker, die durch das Glykogen des Körpers nicht gedeckt waren. Gewiss beziehen sich die von König angegebenen Fettwerthe auf die Schlachtthiere und nicht auf den Hund. Dass auch der Körper der Hunde sehr fettreich sein kann, folgt aus einem Versuche, den ich bereits veröffentlicht habe ${ }^{2}$ ). Das Fleisch eines Hundes, der 28 Tage gehungert hatte, enthielt 19,97\% Fett, also ein Fünftel seines Gewichts war Fett. Obige Zahlen geben aber doch eine Vorstellung,

1) Lüthje, Deutsches Arch. f. klin. Med. Bd. 79 S. 512.

2) E. Pflüg er, dieses Arch. Bd. 91 S. 122. 1902. 
dass die Ableitung der unaufgeklärten $554,4 \mathrm{~g}$ Zucker aus präformirtem Zucker, aus Glykoproteïden und Glycerin keineswegs zu den Unmöglichkeiten gehört. Jedenfalls gehört es zu den Sicherheiten, dass neben dem Glykogen stickstofffreie Stoffe im Organismus vorhanclen sind, welche reichliche Mengen von Zucker zu liefern vermögen, ohne dass man auf die Eiweisskörper zurückzugreifen braucht.

Ehe wir den Versuch $V$ verlassen, wird es nothwendig sein, über noch einen Punkt uns zu verständigen. Die nicht wegzuleugnende Thatsache, dass die Fütterung des Hundes mit Caseïn (Nutrose) eine sehr bedeutende Zuckerausscheidung veranlasst hat, erweckt leicht bei dem diesem Gebiete ferner Stehenden den Glauben, dass der Zucker aus dem Caseïn entstanden ist, dass sich also im Organismus Kohlehydrat aus einem Eiweissstoff gebildet habe. Nun muss man aber daran denken, dass, wenn man einem bisher mit gemischter ausreichender Nahrung ernährten Thier eine Eiweisszulage gibt, sofort im Organismus eine Vermehrung von Fett eintritt. Voit schloss ja daraus, dass das Fett sich aus dem Eiweiss gebildet habe. Wir wissen heute, dass bei diesem Versuch nur desshalb eine Fettablagerung sich vollzieht, weil das gefütterte Eiweiss an Stelle von Fett und Kohlehydrat oxydirt wird, weil also das Eiweiss eine Ersparniss dieser stickstofffreien Stoffe bedingt. Es gibt auch Fälle der indirecten Vermehrung gewisser Bestandtheile unseres Körpers, ohne dass man von einer Ersparniss zu reden berechtigt wäre.

Nach Röhmann ${ }^{1}$ ) bedingt Zufuhr von Ammoniak, nach Külz ${ }^{2}$ ) von Harnstoff, nach Nebelthau ${ }^{3}$ ) sogar von Chloralhydrat oder Chloralamid Vermehrung des Glykogenes der Leber, und dennoch ist es gewiss, dass aus diesen Stoffen kein Glykogen entstehen kann. Es handelt sich um indirecte Beziehungen.

So ist es unzweifelhaft auch bei der Vermehrung der Zuckerausscheidung bei den Diabetikern nach Einnahme von Casein (Nutrose).

Ich habe in meiner Monographie des Glykogens ${ }^{4}$ ) alle bisher angestellten Versuche, durch welche die Zuckerbildung aus Eiweiss, auch aus Caseïn bewiesen werden sollte, rechnerisch einzeln geprüft

1) Röhmann, dieses Arch. Bd. 39 S. 21. 1886.

2) E. Külz, Beiträge zur Kenntniss des Glykogenes S. 27. 1891.

3) Nebelthau, Zeitschr. f. Biol. Bd. 28 S. 138.

4) E. Pflüger, dieses Arch. Bd. 96 S. 227. 1903. 
und gezeigt, wo jedesmal der begangene Fehler liegt. Es hat sich herausgestellt, dass keiner dieser Versuche die Bildung von Kohlehydrat aus Eiweiss beweist. Ich darf sogar sagen, es ist bewiesen worden, dass aus Eiweiss kein Glykogen entsteht.

Dann hat Schöndorff ${ }^{\mathbf{1}}$ ) in einer ausgedehnten und sorgfältigen Untersuchung an einer ungeheuren Zahl von Fröschen gezeigt - unter Umständen, welche die Fehler der individuellen Unterschiede ausschliessen -, dass sicher durch Caseïnfütterung kein Glykogen gebildet wird. Und die Frösche sind bedeutende Glykogenerzeuger.

Die wichtige Arbeit Schöndorff's ist von F. Blumenthal und J. Wohlgemuth ${ }^{2}$ ) vollständig bestätigt worden. Caseïn bewirkte keine Glykogenanhäufung und ebensowenig Leim. Die Fütterung von Ovalabumin, welches ja Zucker enthält, führte zu einer deutlichen Vermehrung des Glykogengehaltes des Körpers.

Es liegt also keine einzige Untersuchung vor, welche bezeugt, dass aus Caseïn im Organismus Kohlehydrat gebildet werden kann. Es ist doch kaum glaubhaft, dass ein diabetischer Organismus Fähigkeiten entwickeln soll, welche dem normalen Organismus grundsätzlich abgehen.

Ein Puukt bleibt noch zu betrachten, der sich auf die Verwerthung der Nutrose durch die misshandelten Verdauungswerkzeuge bezieht. Es musste sichergestellt werden, ob die Nutrose überhaupt resorbirt wurde oder ob sie noch unverdaut im Koth enthalten war. Darüber verlautet in der ganzen Arbeit nichts.

$\mathrm{Lüthje} \mathrm{wird} \mathrm{sich} \mathrm{darauf} \mathrm{berufen,} \mathrm{dass} \mathrm{die} \mathrm{Nutrosengaben} \mathrm{eine}$ Steigerung der Stickstoffausscheidung bewirkten, die ungefähr dem Stickstoffgehalt der gefütterten Nutrose entsprach. Hier liegt nun auch eine Unsicherheit darin, dass Lüthje den Stickstoffgehalt des Harns, nicht aber den der Nutrose angibt. Sein auf den Stickstoffgehalt des Harnes bezüglicher Einwand ist desshalb belanglos, weil sehr oft jeder Anlass, weleher diabetische Zuckerausseheidung bedingt, zugleich eine Steigerung des Stickstoffgehaltes des Harnes zur Folge hat, sogar wenn gar keine Nahrung gereicht wird. Da nun hier eine solche Ursache vorliegt, ist die Stickstoffsteigerung, welche während der Nutrosezufuhr auftrat, nicht sicher aus dieser abzuleiten.

1) B. Schöndorff, dieses Arch. Bd. 82 S. 60.1900.

2) F. Blumenthal und J. Wohlgemuth, Berliner klin. Wochenschr. 1901 Nr. 15 S. 391. 
Wie die Beziehung aufgefasst werden muss, die zwiscben Nutrosezufuhr und Steigerung der Zuckerausscheidung besteht, soll später eingehend gewürdigt werden. Dass es mit der Wirkung der Nutrose eine eigene Bewandtniss hat, geht aus anderen Versuchen Lüthje's hervor, bei denen zwar die Nutrose, nicht aber Serumeiweiss eine Steigerung der Glykosurie veranlasst.

Das dürfte vor der Hand ausreichen, zu zeigen, dass der Versuch V, wie sämmtliche Versuche Lüthje's, gar nichts für die Zuckerbildung aus Eiweiss beweist.

Lüth je $^{1}$ ) aber erklärt, dass dieser Versuch keine andere Deutung zulässt, als "dass der Zucker aus Eiweiss gebildet". "Die Grösse "der Zuckerausscheidung in ihrer Abhängigkeit von der Grösse des „zersetzten Eiweisses (Caseïn) während der Caseinperiode lässt an "Eindeutigkeit nichts zu wünschen übrig."

Es bleibt mir jetzt noch eine in neuerer Zeit erschienene Arbeit von L. Mohr ${ }^{2}$ ) zu erwähnen, welche dasselbe Ziel wie die von Lüthje erstrebt, aber fast ganz auf klinischem Boden steht. Im Wesentlichen handelt es sich auch um die Behauptung, dass der ausgeschiedene Zucker der Diabetiker wegen seiner grossen Menge unmöglich aus den im Organismus präformirten Kohlebydraten abgeleitet werden könne. Dabei benutzt er dann als Maximalwerth die alte, nicht mehr berechtigte Zahl: 1 Kilo Hund $=11 \mathrm{~g}$ Glykogen; durch Schöndorff's Arbeit ist aber der grössere Werth bewiesen :

$$
1 \text { Kilo }=41 \mathrm{~g} \text { Zucker. }
$$

Ausserdem ist die klinische Zahl für die Zuckerausscheidung immer mit Unsicherheit behaftet. Die ganze Abhandlung Mohr's ist durchtränkt von dem Geiste seines Chefs, des Professors Friedrich Kraus in Berlin, dessen Lehren und Beweisführungen in dieser Abhandlung die eingehendste Beurtheilung und Widerlegung zu Theil wird, so dass ich hier auf die Einzelheiten von Mohr's Abhandlung einzugehen verzichten kann.

Dass besonders bei den Klinikern der Glaube an die Zuckerbildung aus Eiweiss so fest wurzelt, hat in erster Linie seinen Grund darin, dass man bei dem experimentellen Diabetes (Phloridzin- oder

1) H. Lüthje, Deutsches Arch. f. klin. Med. Bd. 79 S. 512. 1904.

2) L. Mohr, Ueber die Zuckerbildung im Diabetes mellitus. Zeitschr. f. klin. Med. Bd. 52 s. 337 . Berlin 1904. 
auch Pankreasdiabetes) mit dem Beginn der Zuckerausscheidung auch eine Vermehrung der Stickstoffausscheidung bemerkte und beide in ursächlichen Zusammenhang brachte. Bestärkt wurde man in der Annahme, weil man den Gehalt des lebendigen Organismus an Kohlehydraten gewaltig unterschätzte und die absolute Menge des ausgeschiedenen Zuckers unter Umständen trotz Abwesenheit von Kohlehydrat in der Nahrung so gross war. Es hat sich nun aber herausgestellt, was übrigens schon v. Mering bei seinem Phloridzindiabetes beobachtete, dass die Zuckerausscheidung nicht immer von einer Stickstoffvermehrung im Harne begleitet ist. Ja, Theodor $\mathrm{R} \mathrm{u} \mathrm{m} \mathrm{pf} \mathrm{beobachtete} \mathrm{bei} \mathrm{seinen} \mathrm{berühmten} \mathrm{Phloridzinversuchen,} \mathrm{dass}$ die ungeheuren Zuckerausscheidungen keineswegs von Steigerungen der Stickstoffausscheidungen begleitet waren und gab desshalb für die Erklärung seiner Versuche die Ableitung des Zuckers aus Eiweiss auf.

Ich babe bereits in meiner Monographie ${ }^{1}$ ) angedeutet, wie es sich wahrscheinlich mit der gesteigerten Stickstoffausscheidung verhält, welche oft die gesteigerte Zuckerausscheidung begleitet.

Ich hob hervor, dass die Leber eine Vorrathskammer ist, in welcher grosse Mengen nicht nur von Kohlehydraten, sondern auch von Eiweiss aufgestapelt werien, um zur Zeit des Nahrungsmangels an die übrigen Organe des Körpers abgegeben zu werden. Ich machte darauf aufmerksam, dass die Muskeln, wabrscheinlich aber auch andere Organe, durch ihre Nerven auf reflectorischem Wege nach der Leber telegraphiren, wenn Nahrungsbedarf vorliegt. Dann schüttet die Leber nicht bloss Kohlehydrat, sondern auch Eiweiss in das Blut. In Folge dessen wächst die Eiweisszersetzung. Denn wenn man durch Injection von Blutserum die Eiweissmenge des Blutes vermehrt, findet auch eine Steigerung der Stickstoffausscheidung statt. Da nun, wie ich weiss, je nach den Ernährungszuständen das Verhältniss der Glykogen- zur Eiweissmenge in der Leber ungeheuren Schwankungen unterliegt, so versteht man die grosse Veränderlichkeit der sogenannten Minkowski'schen Zahl. Zucker- und Stickstoffausscheidung wachsen zwar oft gleichzeitig, aber nur desshalb, weil dieselbe Ursache den Eiweiss- und Kohlehydratstoffwechsel steigert. Parallel neben einander laufen beide Vorgänge, aber keiner ist die Ursache des anderen.

1) E. Pflüger, dieses Arch. Bd. 96 S. 386. 
Es gibt aber wahrscheinlich noch eine merkwürdige Ursache, welche beim Diabetiker die Stickstoffausscheidung steigert, obwohl der Zucker nicht aus dem Eiweiss entsteht. Diese merkwürdige Ursache soll später besprochen werden.

Ein anderer Punkt noch wird zu wenig berücksichtigt. Der Diabetiker leidet an Polyphagie, und sein Hunger beweist, dass Nahrungsnoth der Organe besteht. Diese bedingt, dass das Leben auf Kosten des eigenen Leibes und zwar auch auf Kosten von Eiweiss sich vollzieht. Sollte wirklich die Oxydation der Kohlehydrate herabgesetzt sein, versteht man den Nothstand. Je grösser die Zuckerausscheidung ist, desto mehr wächst der Nothstand und mit ihm der Verbrauch an Eiweiss.

\section{\$4. Allgemeines über die Zuckerbildung ans Glycerin und über} Lü th.je's unrichtige Darstellung meiner Stellung zu dieser Frage.

In einer neuesten Arbeit hat $\mathrm{Lühhje}{ }^{1}$ ) den Beweis zu liefern gesucht, dass das Glycerin (und auch das Lecithin) als Zuckerbildner angesehen werden müssen. Auch hier bringt Lüthje eine unrichtige Darstellung meiner und seiner früheren Stellung zu dieser Frage.

In meiner Monographie des Glykogenes sagte ich ${ }^{2}$ ) ausdrücklich: „dass wahrscheinlich das Glykogen nur aus Kohlehydraten oder "diesen nahe verwandten Stoffen sich bilden kann".

Dass zu diesen Stoffen das Glycerin in erster Linie gehört, ist selbstverständlich. Denn ausserhalb des Körpers entsteht durch Oxydation aus Glycerin Glycerinaldehyd und Glycerinketon, welche durch Aldolcondensation zu Zucker zusammentreten.

Bei der Besprechung der Entstehung des Glykogenes aus Fett sagte $\mathrm{ich}^{3}$ ): „Wie jch bereits oben zeigte, ist eine Glykogenbildung "nach Einnahme von Glycerin noch nicht mit Sicherheit dargethan."

An demselben Orte hob ich ${ }^{4}$ ) bervor: "Wäre aber auch unter "Umständen doch das Glycerin des Fettes für die Frzeugung von "Zucker in Betracht zu ziehen, so würde dies wegen des geringen

1) H. Lüthje, Deutsches Arch. f. klin. Med. Bd. 80 S. 98.1904.

2) E. Pflüger, dieses Arch. Bd. 96 S. 169.

3) E. Pflüger, dieses Arch. Bd. 96 S. 289.

4) E. Pflüger, dieses Arch. Bd. 96 S. 122. 
„Betrages, mit dem das Glycerin im Fett enthalten ist, von geringer "praktischer Bedeutung sein."

Ferner: Nachdem ich bei einem Hunde, der 28 Tage gehungert hatte, noch 4,785\% Glykogen (als Zucker berechnet) in der Leber fand und gleichzeitig im Fleisch eine ungeheure Fettmenge, sagte ich:

„Die erstaunlich hobe Menge des Glykogenes in der Leber trifft „mit einer anderen merkwürdigen, bei diesem Hunde beobachteten "Thatsache zusammen, die vielleicht hierbei von Bedeutung ist." Damn bringe ich die Analysen, welche den grossen Fettreichthum des Thieres bezeugen.

Aus diesen Citaten erkennt man, dass ich die Zuckerbildung aus Glycerin als eine Möglichkeit gelten liess.

Da aber grosse Fettgaben oder Oelinjectionen bei Diabetikern keine Vermehrung der Zuckerausscheidung zur Folge haben, schloss ich, wie das ja fast alle anderen Forscher auch getban haben, dass das Fett als Zuckerquelle nicht anzuerkennen sei.

Wegen dieser meiner Stellung macht $L$ ü thj $\mathrm{e}^{2}$ ) die Bemerkung: "Trotzdem haben wir meines Erachtens noch keinen Anlass, allein "auf Grund der Pflüger'schen Angaben sofort die Möglichkeit "einer Zuckerbildung aus Fett als abgetban anzusehen."

Jeder sieht, dass Lüthje hier eine unwahre Darstellung meiner Auffassung gibt. Ich hatte nur die Zuckerbildung aus Fett „noch nicht" als erwiesen, nicht aber als abgethane Sache bezeichnet.

Man kann kaum glauhen, dass Lüthje selbst einige Monate vor Veröffentlichung meiner Monographie noch genau dieselbe Stellung wie ich zur Frage der Zuckerbildung aus Fett einnahm. In seinem am 30. September 1902 erschienenen Aufsatz ${ }^{3}$ ) "Zu r Frage der Zuckerbildung im Organismus" sagt Lüthje: "In einer Reihe von Versuchen an pankreaslosen Hunden, die ich "in dem letzten Jahre gemacht habe, habe ich des Weiteren Resul"tate bekommen, die durchaus nicht dafür sprechen, dass "bei Verabreichung von Neutralfetten aus diesen sich "Zucker bilde." In derselben Abbandlung erklärt Lüthje ferner: "Aus einer Reihe von Versuchen, die ich im letzten Jahre „angestellt habe, theile ich einige mit, die mir für die An-

1) F. Pflüger, dieses Arch. Bd. 96 S. 290.

2) H. Lüthje, Deutsches Arch. f. klin. Med. Bd. 80 .

3) H. Lüthje, Münchner med. Wochenschr. Nr. 39 S. 1601. 
"nahme, dass aus Fett kein Zueker gebildet würde, "recht beweisend zu sein scheinen" u. s. w.

In seiner neuesten, 1904 erschienenen Arbeit über „d i e Zuckerbildung aus Glycerin" erklärt jetzt Lüthje ${ }^{1}$ ) im Widerspruch zu seinen früheren Ansichten:

"Trotzdem haben wir meines Erachtens noch keinen Anlass, „allein auf Grund der Pflüger'schen Angaben sofort die Möglich"keit einer Zuckerbildung aus Fett als abgethan anzusehen." „Denn "die Einwände Pflüger's gegen die von Cremer entdeckte "Zuckerbildung aus Glycerin vermag ich auf Grund der jetzt mit"zutheilenden Versuche nicht als stichhaltig anzuerkennen."

Nun ist zu beachten, dass Lütbje selbst die Berechtigung meines gegen Cremer erhobenen Einwandes anerkannte und zu dessen Widerlegung Versuche anstellte, von denen er zugab, dass sie nicht streng beweisend erscheinen.

Ich $^{2}$ ) hatte unter Anderem darauf hingewiesen, dass die von Cremer ${ }^{2}$ ) beobachtete Steigerung der Zuckerausscheidung nach Einnahme von Glycerin bei Hunden, die mit Phloridzin vergiftet waren, möglicherweise durch die starke diuretische Wirkung ${ }^{4}$ ) des Glycerins bedingt sei, welche eine grössere Ausschwemmung des Zuckers ermögliche. Nun hat Lü thje bereits 1902 zur Entkräftung dieses Einwandes einem durch Phloridzin diabetischen Hunde Kochsalzlösung unter die Haut gespritzt, ohne eine deutliche Stejgerung der Zuckerausscheidung zu erzielen. Lüthje ${ }^{5}$ ) sagt selbst: „Ob „übrigens der Controlversuch mit subcutaner Kochsalzinfusion aus„reicht, um den Einwurf, es könnte sich um eine diuretische Wirkung. "des Glycerins handeln, auszuschliessen, bleibt zweifelhaft."

Hiermit hat Lütbje die noch fortbestebende Berechtigung meines gegen $\mathrm{Cremer}$ erhobenen Einwandes selber anerkannt.

Die in der neuesten Arbeit von Lü thje zu Gunsten Cremer's beigebrachten Beweise werden wir indessen bald als ungenügende feststellen.

Vorher muss ich aber noch Einsprache erheben gegen die Behauptung Lüt hje's, derzufolge Crem er das Glycerin als Zuckerbildner

1) Lüthje, Deutsches Arch. f. đ. klin. Med. Bd. 90 S. 99.

2) E. Pflüger, dieses Arch. Bd. 96 S. 288.1903.

3) M. Cremer, Ergebnisse der Physiol. Bd. 1 Abth. 1 S. 889. 1902.

4) C. Ustimowitsch, dieses Arch. Bd. 13 S. 453. 1876.

5) H. Lüthje, Deutsches Arch. f. klin. Med. Nr. 89. 1902. 
entdeckt habe. Nur die vollkommene Unkenntniss der einschlägigen Literatur macht solchen Irrthum begreiflich. Es existirt eine recht grosse Zahl von Untersuchungen, durch welche die Entstehung von Glykogen oder die Steigerung der diabetisehen Zuckerausscheidung nach Fütterung von Glycerin festgestellt worden ist. Schon C. Schmidt ${ }^{1}$ ) stellte 1850 die Ansicht auf, dass Glycerin im Organismus in Zucker übergehe. Berthelot ${ }^{2}$ ) gab an, durch Digestion von Glycerin mit Hodensubstanz gährungsfähigen Zucker erhalten zu haben. Durch die Untersuchungen von van Deen ${ }^{3}$ ) und Heynsius ${ }^{4}$ ) ist die Entstehung von Glykogen aus Glycerin vielfach untersucht. Weiss ${ }^{5}$ ), Salomon ${ }^{6}$ ), Luchsinger ${ }^{7}$ ), Finn ${ }^{8}$ ), v. Mering ${ }^{9}$ ) und Andere bringen Versuche, bei denen Fütterung von Glycerin eine Vermehrung des Leberglykogenes veranlasst haben soll. Dr. Frey ${ }^{10}$ ) untersuchte bei einem unter Verschluss gehaltenen Diabetiker den Einfluss der Glycerinbehandlung. Der Patient war auf reine Fleisehdiät gesetzt. Die Glycerinperiode währte vom 26. April bis 3. Mai, während täglich $50 \mathrm{~g}$ Glycerin gereicht wurden. Die tägliche 24 stündige Zuckermenge betrug vor dem Beginn der Glyceringabe $258 \mathrm{~g}$ und stieg auf $300,6 \mathrm{~g}$. - Es lassen sich in der Literatur sicher noch mehr Arbeiten auffinden, durch welche eine scheinbare, oft nicht unerhebliche Vermehrung der Kohlehydrate des Organismus nach Glyceringaben beobachtet worden ist.

Es fragt sich jetzt, ob der bis dahin nicht mit hinreichender Strenge geführte Beweis durch die letzte Arbeit von Lüthje erbracht worden ist.

1) C. Schmidt, Charakteristik der Cholera. 1850.

2) Berthelot, Ann. d. Chim. et Phys. [3] t. 50 p. 346.

3) van Deen, Ueher Bildung von Zucker aus Glycerin im Thierkörper. Arch. f. holl. Beiträge Bd. 3 S. 25 u. S. 61. 1861.

4) A. Heynsius, Die Quelle des Leberzuckers. Studien des physiol. Institutes zu Amsterdam S. 57. 1861.

5) Weiss, Wiener akad. Sitzungsber. Bd. 64 Abth. 2 u. Bd. 67 Abth. 3.

6) Salomon, Ueber die Bildung des Glykogenes in der Leber. Virchow's Arch. Bd. 61 S. 348. 1874.

7) B. Luchsinger, Experimentelle und kritische Beiträge zur Physiologie und Pathologie des Glykogenes. Inaugural-Dissertation. Zürich 1875.

8) Benjamin Fin n, Zur Glykogen-, und Zuckerbildung in der Leber. Verhandlungen der physik.-med. Gesellschaft in Würzburg N. F. Bd. 11. 1877.

9) v. Mering, Zur Glykogenbildung in der Leber. Dieses Arch. Bd. 14 S. 277.1876 .

10) Maly's Jahresbericht für 1874 S. 434. 


\section{§. Beurtheilung der einzelnen Glycerinversuche Lü thje's.}

$$
\text { Lüthje's Versuch I (S. 99). }
$$

Einem Hund von 13,ó Kilo, über dessen Ernährungszustand Nichts angegeben ist, wird das Pankreas am 5. August exstirpirt. Nach der Operation hungert der Hund bis zum 23. August also 19 Tage und erhält $50 \mathrm{~g}$ Glycerin am 19 . Hungertage und nochmals $50 \mathrm{~g}$ Glycerin am 23. Hungertage. Während er am Tage vor der ersten Glyceringabe nur 0,9 o Zucker ausschied, steigt die Ausscheidung nach dem Glycerin am ersten Tag auf 11,28, sinkt am zweiten auf 5,35 und am dritten wieder auf 0,55. Die zweite Gabe von $50 \mathrm{ccm}$ Glycerin bedingt wieder eine Steigerung auf $11,4 \mathrm{am}$ ersten Tag, die am zweiten auf 3,9 zurückgeht. Die Glyceringaben haben unzweifelhaft eine Steigerung der Zuckerausscheidung bewirkt. Alle Forscher aber, welche sich auf diesem Gebiete bewegten, gaben zu, dass durch solche Steigerung noch nicht die Umwandlung des gefütterten Stoffes in Zucker bewiesen ist. Es kann sich um eine indirecte Wirkung handeln. Die Gesammtmenge von Zucker, welche das Thier vom 5 . bis 28. August ausschied, betrug 86,5 g. Da der Hund am Anfange $13,5 \mathrm{~kg}$ wog, konnte er in maximo $553,5 \mathrm{~g}$ Zucker aus Glykogen liefern, d. h. sechs Mal so viel als er thatsächlich ausgeschieden hat. Der Versuch beweist also Nichts.

$$
\text { Lüthje's Versuch II (S. 99). }
$$

Einem Hunde von 13 Kilo wird am 20. August das Pankreas exstirpirt. Das Thier erhält keine Nahrung und scheidet vom 21 . bis 25. August (dem Todestag) 191,74 g Zucker aus. Da das Thier in maximo bei 13 Kilo Anfangsgewicht $533 \mathrm{~g}$ Zucker liefern konnte, hat man nicht nöthig, bei Aufsuchung der Zuckerquelle auf einen anderen Stoff als Glykogen zurückzugreifen. Am Todestag erhielt der Hund eine Gabe von $50 \mathrm{ccm}$ Glycerin, wodurch eine geringe Steigerung der Zuckerausscheidung bedingt wurde - von 37,72 auf $45,72 \mathrm{~g}$. - Der Versuch beweist also nichts.

Lüthje's Versuch III (S. 101).

Einem "gutgenährten" Dachshund, dessen Gewicht nicht angegeben wird, wurde am 15. April das Pankreas exstirpirt. Der Hund erhielt keine Nabrung, abgesehen davon, dass ihm am 17. u. 18. Hungertage 75 , resp. $15 \mathrm{~g}$ Nutrose gereicht wurden, welche, ob- 
wohl der Hund bisher zuckerfrei war, einè Ausscheidung von 8,5, resp. 7,0 g Zucker veranlassten. - Am 31. Hungertage bewirkte eine Dosis von $20 \mathrm{ccm}$ Glycerin eine Zuckerausscheidung von $6,2 \mathrm{~g}$, am 33. Hungertage auf die Verabreichung von $40 \mathrm{ccm}$ Glycerin eine Zuckerausscheilung von 14,0 g. Am 35. Hungertag war der Harn wieder zuckerfrei.

Der Hund schied also, nachdem er 30, resp. 33 Tage gehungert hatte, nach Einnahme von $60 \mathrm{ccm}$ Glycerin im Ganzen $20,2 \mathrm{~g}$ Zucker aus.

Ich habe über den Glykogengehalt eines Hundes berichtet, der 28 Tage gehungert hatte und aus dem Glykogen seines Körpers $52,504 \mathrm{~g}$ Zucker hätte liefern können ${ }^{1}$ ). Nun war dieser Hund allerdings viel schwerer als der Dachshund von $\mathrm{Lüh}$ thje, von dem das Gewicht nicht angegeben ist. Gleichwohl zeigt mein Versuch, dass selbst nach sehr langer Hungerzeit ein Hund noch immer in seinem Körper nicht unerhehliche Mengen von Koblehydrat beherbergen kann. Da es sich nun ausserdem in diesem Versuch III Lüthje's um sehr kleine Zuckermengen handelt, beweist auch dieser Versuch nichts.

$$
\text { Lüthje's Versuch IV (S. 101). }
$$

Nach 2 Hungertagen wird einem Schäferhund von 15,2 Kilo am 30. Januar von Herrn Professor Küttner das gesammte Pankreas exstirpirt. Das Thier erhält bis zum 7. Februar keine Nahrung, ist am 6. Februar schon zuckerfrei, nachdem es vorher kleine Zuckermengen ausgeschieden hat. Am 7. Februar erhält der Hund $100 \mathrm{~g}$ und am 8. Februar $150 \mathrm{~g}$ Nutrose und scheidet $24 \mathrm{~g}$, resp. $37,7 \mathrm{~g}$ Zucker aus. Also $250 \mathrm{~g}$ Nutrose (der Gehalt an N, Asche, Feuchtigkeit ist nicht angegeben und folglich nur eine ungefähre Rechnung möglich) erzeugen eine Absonderung von $61,7 \mathrm{~g}$ Zucker, oder es haben $100 \mathrm{~g}$ Nutrose scheinbar $24,6 \mathrm{~g}$ Zucker gebildet.

Am 9. u. 10. Februar erbält der Hund je $500 \mathrm{ccm}$ Serum und erzeugt am 9. Februar 3,5 g, am 10. Februar aber keinen Zucker. Da die Zuckerausscheidung am 9. Februar wohl als Nachwirkung anzusehen ist, folgt, dass $1000 \mathrm{ccm}$ Serum $=$ ungefähr $80 \mathrm{~g}$ Eiweiss keine Zuckerausscheidung veranlassten, während $100 \mathrm{~g}$ Nutrose, die ebenfalls vielleicht nicht viel mehr als $80 \mathrm{~g}$ Eiweiss entsprechen, $24,6 \mathrm{~g}$

1) Dieses Arch. Bd. 96 S. 168. 
Zuckerausscheidung veranlassten. Das ist ein verdächtiger Punkt. Serumeiweiss macht keine, Nutrose beträchtliche Zuckerausscheidung. Vom 11. Februar bis 24. Februar erhält der Hund nun täglich grosse Mengen eines Gemisches von Serum und Glycerin und scheidet sehr grosse, den zugeführten Eiweissmengen ungefähr proportionale Mengen von Zucker aus.

In der grossen Versuchsperiode vom 11. bis 24. Februar, wo der Hund im Ganzen aufnahm:

$12750 \mathrm{ccm}$ Serum $=$ ca. $1020,00 \mathrm{~g}$ Eiweiss,

$2890 \mathrm{ccm}$ Glycerin,

schied er 1322,7 g Zucker aus.

Rechnet man vom Anfange des Versuches an, so beträgt der gesammte ausgeschiedene Zucker

$$
1408,4 \mathrm{~g} \text {. }
$$

Da der Hund im Anfang 15 Kilo wog, so konnte er liefern $51 \times 41 \mathrm{~g}=615 \mathrm{~g}$ Zucker.

$1408,4 \mathrm{~g}-615 \mathrm{~g}=793 \mathrm{~g}$ Zucker sind also ungedeckt durch das präexistirende Glykogen. Diese Werthe sind von mir berechnet. Denn hier hatte sich $L u ̈ t h j e ~ z u$ seinen Ungunsten verrechnet.

Es handelt sich nun zuerst um die Frage, wie viel Zucker das während der Versuchsdauer zersetzte Eiweiss liefern konnte. Der Hund hat 209,8 g Stickstoff ausgeschieden. Lüthje nimmt nun ohne nähere Begründung an, dass $1 \mathrm{~g} \mathrm{~N} 3 \mathrm{~g}$ Zucker geliefert haben könne, wodurch nach ihm $630 \mathrm{~g}$ Zucker gedeckt wären. Also $793-630 \mathrm{~g}=163 \mathrm{~g}$ Zucker wären also auch durch das präexistirende Glykogen und den aus dem Eiweiss gebildeten Zucker nicht gedeckt.

Die Annahme Lüthje's, dass bei der Zuckerbildung aus Eiweiss auf $1 \mathrm{~g} \mathrm{~N} 3 \mathrm{~g}$ Zucker kommen, ist die reine Willkür; desshalb kann man auch $1 \mathrm{~g} \mathrm{~N}$ viel mehr Zucker entsprechen lassen. Dass dies erlaubt ist, ergibt sich aus folgender Rechnung.

Setzt man $100 \mathrm{~g}$ Eiweiss $=16 \mathrm{~g} \mathrm{~N}$ und nach Lüthje für $100 \mathrm{~g}$ Eiweiss

$$
3 \times 16 \mathrm{~g}=48 \mathrm{~g} \text { Zucker }=19,2 \mathrm{~g} \text { Kohlenstoff. }
$$

Ferner $100 \mathrm{~g}$ Eiweiss liefern aber aus $16 \mathrm{~g} \mathrm{~N}=34 \mathrm{~g}$ Harnstoff $=$ $6,8 \mathrm{~g}$ Kohlenstoff. Folglich bleiben, wenn wir $100 \mathrm{~g}$ Eiweiss $=$ $52 \mathrm{~g}$ Kohlenstoff: $52-6,8 \mathrm{~g}=45,2 \mathrm{~g}$ zur Verfügung. Von diesen nimmt $L \ddot{u} t h j$ e nur $19,2 \mathrm{~g}$ in Anspruch, also noch nicht die Hälfte. Diese Hälfte genügt schon zur Erklärung von $630 \mathrm{~g}$ Zucker. Um 
die noch nicht erklärten $163 \mathrm{~g}$ aus dem Eiweiss abzuleiten, hat man von dem reichlich zur Verfügung stehenden Kohlenstoff des Eiweisses etwas mehr in Rechnung $\mathrm{zu}$ stellen, so ist aller ausgeschiedene Zucker durch präexistirendes Glykogen und Eiweiss gedeckt.

Die ganze Beweisführung L üthje's wird dadurch erreicht, dass er als Multiplicator für $1 \mathrm{~g} \mathrm{~N}$ die Zahl 3 annimmt, um die aus Eiweiss mögliche Zuckermenge zu berechnen. Nun schwankt aber der hier in Betracht gezogene Quotient $\frac{D}{N}$, d. h. das Verhältniss der ausgeschiedenen Menge der Dextrose zu der des Stickstoffs, von 0 bis über 10. Das geht aus den Untersuchungen von Graham $\operatorname{Lusk}^{1}$ ), v. Mering${ }^{2}$ ), Minkowskiª), Moritz und Prausnitz ${ }^{4}$ ), Cremer und Ritter ${ }^{5}$ ) u. s. w. hervor.

Will man von den vielen sehr verschiedenen beobachteten Werthen von $\frac{D}{N}$ nur den einen Werth 3 gelten lassen, so muss man allen Zucker, der für den Werth $3 \mathrm{zu}$ gross ist, aus anderem Ursprung als Eiweiss ableiten, also Bestimmtes hierüber voraussetzen in derselben Betrachtung, welche erst den Grad der Betheiligung des Eiweisses bei der Zuckerbildung feststellen soll. Das ist ein innerer Widerspruch. Höhere beobachtete Multiplicatoren als die von Lüthje benutzte Zahl 3 sind ebenso berechtigt oder unberechtigt. Ein nur wenig höherer Multiplicator bringt also das angebliche Deficit zum Versehwinden, wodurch der Beweis Lüthje's widerlegt wird.

Der Beweis für die Entstehung des Zuckers aus dem Glycerin ist also nicht geliefert, solange man daran festhält, dass die Eiweissmoleküle, auch wenn sie keine Kohlehydrate enthalten, dennoch in Zucker umgeprägt werden können.

Wie steht die Sache aber von meinem Standpunkt, der die Zuckerbildung aus Eiweiss verwirft?

Der Hund schied 1408,4 g Zucker aus, von denen $793 \mathrm{~g}$ durch

1) Graham Lusk, Zeitschr. f. Biol. Bd. 36 S. 82.1898.

2) v. Mering, Verhandlungen des V. Congresses für innere Medicin S. 185. 1886. - Verhandlungen des VI. Congresses für innere Medicin S. 349. 1887. Zeitschr. f. klin. Medicin Bd. 14 S. 405. 1888. - Zeitschr. f. klin. Medicin Bd. 15 S. 431. 1889. - Zeitschr. f. klin. Medicin Bd. 16 S. 439.

3) Minkowski, Arch. f. exper. Pathol. u. Pharmak. Bd. 31 S. 85.1893.

4) Moritz und Prausnitz, Zeitschr. f. Biol. Bd. 27 S. 81.1890.

5) Cremer und Ritter, Zeitschr. f. Biol. Bd. 28 S. 459.1891. 
das präexistirende Glykogen nicht gedeckt sind. Da der Hund 15 Kilo wog, müssten noch $5,3 \%$ Koblehydrate in Form von freiem Zucker oder Glykoproteiden und Glykosiden im Körper des Hundes neben $4 \%$ Glykogen vorbanden sein. Da die Leber allein bis zu $20 \%$ Kohlehydrat an Glykogen enthalten kann, so ist a priori die Möglichkeit, dass der Gesammtkörper $5 \%$ Kohlehydrat in anderer, zum Theil noch unbekannter Form enthält, nicht unbedingt zu verwerfen. Unsere Methoden zum Nachweise der gebundenen Kohlehydrate sind noch viel zu unvollkommen, als dass ich mir ein so absprechendes Urtheil hier erlauben wollte, wie es manehe Kliniker thun. Es ist also auch, von meinem Standpunkte aus, die Zuckerbildung aus Glycerin durch Lüthje nicht bewiesen. Die Beweisführung, welche manche Kliniker belieben, gipfelt in dem Satze: Was man noch nicht nachweisen kann, muss als Null in die Rechnung eingesetzt werden.

\section{\$ 6. Ueber die Zackerbildung ans Fett.}

Nachdem ich bewiesen habe, dass eine Nöthigung zur Annahme der Zuckerbildung aus Glycerin durch den Versuch IV Lüthje's nicht gegeben ist, fragt es sich, ob das Nicht-Bewiesene doch wahrscheinlich sei. -

Ich gebe zu, dass die in die Rechnung eingesetzte präformirte Glykogenmenge wahrscheinlich zu hoch ist. Man könnte ferner den Satz aufstellen, dass das Glycerin nur auf indirecte Weise die Zuckerausscheidung gesteigert hat, weil es an Stelle des Zuckers oxydirt wurde und so eine Ersparniss an Zucker veranlasst habe. Dann müsste man zugeben, dass zu den Zeiten, wo kein Glycerin gefüttert und keine oder nur geringe Zuckerausscheidung bestand, trotzdem im Körper ein erheblicher Verbrauch von Zucker vorhanden war. Das würde die Grösse der nicht gedeckten Zuckermenge noch weiter steigern. Man müsste, wollte man trotzdem das Glycerin als Zuckerbildner nicht anerkennen, den Glykosiden einen Betrag zuschieben, dessen Höhe auch unwahrscheinlich ist. Eine grössere Zahl neuerer Untersuchungen haben also die Ableitung der grossen, im Diabetes ausgeschiedenen Zuckermengen aus den Kohlehydratvorräthen des lebendigen Körpers in bohem Grade unwahrscheinlich gemacht. Da nun das Eiweiss sicher als Zuckerquelle nicht anerkannt werden kann und das Glycerin seiner geringen 
Menge halber auch schwerlich ausreicht, bleiben nur die Fette als Muttersubstanzen des Zuckers in Erwägung zu ziehen.

Es bleibt nun, was ja alle Forscher auf diesem Gebiete hervorheben, das Räthsel, wesshalb bei keiner Art von Diabetes die Zufuhr von Neutralfett eine Steigerung der Zuckerausscheidung bedingt, obwohl im Darme Glycerin neben Fettsäuren entsteht. - Indem ich die Lösung des Räthsels versuche, will ich die Thatsachen gelten lassen, d. h. voraussetzen, dass das zugeführte Glycerin im Organismus stets wie genossenes Eiweiss sofort der Oxydation anheimfällt, während gefüttertes oder injicirtes Fett unangegriffen bleibt.

Das mit der Nahrung zugeführte Neutralfett wird allerdings im Darme in Fettsäure und Glycerin gespalten, aber nach der Resorption in der Epithelzelle der Darmwand sofort in Neutralfett zurückverwandelt. Deshalb gelangt nur Neutralfett und kein oder auch nur wenig Glycerin in den Organismus.

Vor Eintritt in Einzelheiten hebe ich das grosse Grundgesetz des thierischen Stoffwechsels hervor: Der lebendige Körper ist nicht einer grossen Esse vergleichbar, auf der um so mehr verbrennt, je mehr Brennmaterial darauf geworfen wird, sondern er oxydirt, wie viel Brennmaterial auch immer zugeführt wird, nur genau so viel, als nothwendig ist, um die Leistungen der Organe zu ermöglichen. Was an Brennmaterial, d. h. an Nahrung zu viel gereicht wird, bleibt unbenutzt und wird als Maststoff abgelagert. Also nicht die Grösse der Nahrungszufuhr, sondern die Grösse der Arbeit nuserer Organe bestimmt die Grösse des Verbrauchs.

Vorerst gedenken wir nunmehr an die wichtige Entdeckung von Carl Voit, die ich in ausgedehnter Weise bestätigt habe, derzufolge der Fettstoffwechsel zur Ruhe kommt, wenn eine ausreichende Menge von Eiweiss mit der Nahrung zugeführt wird. Das Thier lebt dann nur von Eiweiss, und zwar beliebig lange Zeit. Dieser Zustand kommt nun strenge und nur unter Umständen bei den Fleischfressern vor, niemals bei den Omnivoren und Herbivoren. Die Eiweissmenge, welche die Omnivoren in der Nahrung aufnehmen, reicht niemals zur Befriedigung der Bedürfnisse des Organismus aus; kann nicht ausreichen, weil bei diesen Geschöpfen die Verdauungskraft nicht gross genug ist, um eine Eiweissmenge zu bewältigen; welche zur Befriedigung aller Bedürfnisse genügt. Darum wird der Stoffwechsel bei den Omnivoren immer auch auf Kosten der Fette und Kohlehydrate unterhalten. Aber auch hier ist die Grösse dieser 
Betheiligung sehr verschieden. Denn Fett und Kohlehydrate werden nur zum Stoffwechsel zugelassen, um den Nahrungswerth zu ergänzen, welcher dem in der Nabrung zugeführten Eiweisse fehlt. Da aber an verschiedenen Tagen die Nahrungsmischung, also auch der Eiweissgehalt derselben wechselt, so ist der Werth der Ergänzung sehr verschieden. Demnach jst der Stoffwechsel der Fette und der Kohlehydrate in erster Linie von der zugeführten Eiweissmenge abhängig und ibr umgekehrt proportional. Wir können auch so sagen: Die Grösse des Eiweissstoffwechsels wird durch die Grösse der Eiweisszufuhr bestimmt; die Grösse des Fettstoffwechsels ist von der Grösse der Fettzufuhr ganz unabhängig.

Die mitgetheilten Gesichtspunkte erklären bereits einige Sonderbarkeiten, die man sich bisher nicht erklären konnte, wenn man eine Zuckerbildung aus Fett annahm.

Warum zugeführtes Fett keine Aenderung der Zuckerausscheidung bei dem Diabetiker bedingt, hat seinen Grund darin, dass die Fettmenge, welche im Organismus verarbeitet wird, eine ganz be stimmte Grösse nicht überschreiten kann, und dass stets viel mehr Fett in uns aufgespeichert ist, als nothwendig wäre, um jener bestimmten Grösse zu genügen. Die Zufubr von Fett vergrössert also nur den ohnedies schon unbenutzbaren Vorrath. Was beim Diabetiker von Zucker aus Fett geliefert wird, hängt folglich gar nicht von der Menge des vorhandenen Fettes ab.

Ein anderer bisher unerklärter Punkt war, dass die Zufuhr von Fett keine deutlichen Glykogenablagerungen ermöglicht. Wir haben gesehen, dass vermöge der festen Gesetze des Stoffwechsels das Fett ạls Ergänzung herangezogen wurde bis zur Befriedigung des Bedarfs, aber nicht über diesen Betrag, wenn auch ein noch so grosser Ueberschuss an Fett da ist. Wenn also auch aus Fett fortwährend beim Stoffwechsel Zucker entsteht, so wird dieser auch sofort verbraucht und kann kein Material zur Bildung eines Reservestoffs wie Glykogen liefern.

Wir wissen nun, dass das Fett im Organismus oxydirt wird. Ebenso gewiss ist aber, dass das Fett indifferent gegen Sauerstoff ist, so dass eine vorbereitende Bearbeitung des Fettes zur Ermöglichung der Oxydation vorausgesetzt werden darf. Eine Spaltung des Neutralfettes gibt wenigstens einem Bestandtheil desselben, dem Glycerin, die Fähigkeit, leicht oxydirt zu werden und hierdurch Zucker zu bilden. Es fragt sich nun, ob die bei den Pflanzenzellen 
vorkommende, von Julius Sachs ${ }^{1}$ ) nachgewiesene Fähigkeit, aus Fetten Zucker zu bilden, vielleicht auch beim Thiere vorhanden ist. Eingeschüchtert durch die nicht verstandene, von mir jezt aufgeklärte Thatsache, dass Fettnahrung keine Vermehrung des Glykogenes und bei Diabetikern keine Steigerung der Zuckerausscheidung bewirkt, obwohl aus Fett im Organismus fortwährend Zucker entsteht, waren Kliniker und Physiologen immer der Annahme abgeneigt, dass die Fette oder gar die Fettsäuren als Zuckerbildner aufgefasst werden könnten. Ich glaube aber jetzt, dass diese Möglichkeit - die bei den Pflanzen Wirklichkeit ist - eine wohlwollende Prüfung erheischt.

Wenn wir also einmal den Gedanken der Entstehung von Zucker aus Fett zulassen, so ist es klar, dass solche Verwandlung nur durch eine Arbeit der lebendigen Zellsubstanz verwirklicht werden kann. Am stärksten muss diese Arbeit der Zellsubstanz sich bethätigen, je höher der Fettstoffwechsel entwickelt ist. Das sind die Zeiten des Nahrungsmangels, wie sie den Diabetes begleiten.

Fr. N. Schulz ${ }^{2}$ ) hat in der That in meinem Laboratorium nachgewiesen, dass das Blut während des Hungerns fettreicher wird. Auch beim Diabetes mellitus berichtet $\mathrm{Kussmaul}{ }^{3}$ ) über einen reichen Fettgehalt des Blutes. Wir finden hier offenbar das Fett auf dem Wege noch als Fett nach den Werkstätten, wo es weiter verarbeitet werden soll. Auch Dr. Leo Schwarz ${ }^{4}$ ) ist durch seine Untersuchungen zu dem Ergebniss gelangt, „dass der Fettgehalt des "Diabetikerblutes auch ausserhalb der Fettverdauung etwas grösser" ist, als der des Nichtdiabetikers.

$\mathrm{Ob}$ nun die Werkstätten, wo das Fett verarbeitet wird, etwa in der Leber liegen oder in allen Zellen, ist vor der Hand nicht zu entscheiden. Seegen ${ }^{5}$ ) hat ja bekanntlich durch Versuche zu zeigen gesucht, dass Digestion von Léberbrei mit Fett und Blut eine Vermehrung des Zuckers bedinge. Der Versuch ist in neuerer Zeit

1) Julius Sachs, Vorlesungen über Pflanzenphysiologie, 2. Aufl. S. 318. Botanische Zeitung 1859. Peter's landwirth. Versuchsstationen Bd. 3. 1861.

2) Fr. N. Schulz, Ueber den Fettgehalt des Blutes beim Hunger. Dieses Arch. Bd. 65 S. 66.

3) Kussmaul, Zur Lehre vom Diabetes mellitus. Arch. f. klin. Med. Bd. 14. (Maly's Jahresber. von 1874. S. 433.)

4) Dr. Leo Schwarz, Deutsches Arch. f. klin. Med. Bd. 77 S. 279.1903.

5) Seegen, dieses Arch. Bd. 999 S. 132. 1886. Die Zuckerbildung im Thierkörper S. 151. 1890. 
von E. Abderhalden und P. Rona ${ }^{1}$ ) wiederholt, aber als unrichtig verworfen worden. Man muss indessen in Betracht ziehen, dass die Zuckerbildung aus Fett eine Lebensarbeit der lebendigen Zellsubstanz sein wird, wesshalb das Gelingen des Seegen'schen Versuches von vornherein sehr erschwert war. Die Leber könnte also doch das Organ sein, welches nicht bloss aus Glykogen, sondern auch aus Fett Zucker bereitet.

Wie kann man sich nun die Entstehung von Zucker aus Fett erklären?

Es fällt auf, dass im Organismus öfters Kreisprocesse vorkommen. Im Dünndarm wird das Neutralfett in Fettsäure und Glycerin gespalten und in der resorbirenden Epithelzelle aus seinen Spaltungsproducten sofort wieder zusammengesetzt. Hydrolyse und Esterbildung folgen einander. - In der Leber seben wir den Zucker in Glykogen übergehen und in derselben Zelle wieder das Glykogen zurück in Zucker verwandelt werden: dort Esterbildung, hier Hydrolyse. - Das Gewebe der Pankreas hydrolysirt oder esterificirt je nach den Umständen. - Sollte diesem Gesetz nicht allgemeinere Geltung zukommen? Sollte im Körper nicht bloss Zucker in Neutralfett, sondern auch Neutralfett in Zucker zurückverwandelt werden können? Hier kann es sich allerdings nicht bloss um Hydrolyse und Esterbildung handeln. Wie aus den Untersuchungen von Max Bleibtre ${ }^{2}$ ) hervorgeht, ist die Fettbildung aus Zucker ein der alkoholischen Gährung analoger Vorgang. Ein Theil des Zuckermoleküles wird oxydirt unter Bildung von Koblensäure, der andere Theil wird reducirt. Es handelt sich im Wesentlichen um eine intramolekulare Wanderung der Sauerstoff- und Wasserstoffatome, welche zu einem Zerfall des Zuckermoleküles in einen oxydirten und reducirten Bestandtheil führen. Bei der Bildung des Fettes aus Zucker entsteht auch ein oxydirter Bestandtheil, die Kohlensäure, welche ausgeathmet wird, und ein reducirter, nämlich das Fett. Im Wesentlichen läuft die Reaction hinaus auf die Spaltungs-Gleichung:

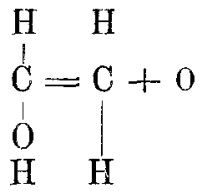

1) E. A bderhalden und P. Rona, Bildung von Zucker aus Fett. Zeitschrift f. physiol. Chemie. Bd. 41 S. 303.1904.

2) Max Bleibtreu, dieses Arch. Bd. 56 S. 464 und Bd. 85 S. 345. 
Ueb. die im thier. Körper sich vollziehende Bildung von Zucker etc.

und die Zurückbildung auf die Gleichung:<smiles></smiles>

Es ist von Wichtigkeit, nach der Mechanik der bei dieser Zuckerbildung ins Spiel gesetzten chemischen Reactionen zu fragen, für welche nach Analogie geschlossen werden muss.

Da das Molekül der Fettsäure eine Kohlenstoffkette bis zu 18 Atomen, ja noch mehr enthält, während sie beim Zuckermolekül nur 6 beträgt, so ist es klar, dass die lange Kohlenstoffkette in mehrere kürzere Ketten zerfallen muss, deren jede 6 C-Atome enthält. Für die Sprengung der langen Kette liefert uns die alkoholische Gährung ein gutes Beispiel, weil hier eine Kette von 6 CAtomen in 4 Theile gesprengt wird, und zwar durch Oxydation zweier C-Atome zu Kohlensäure. Am besten macht man sich die alkoholische Gährung durch folgendes Schema klar.

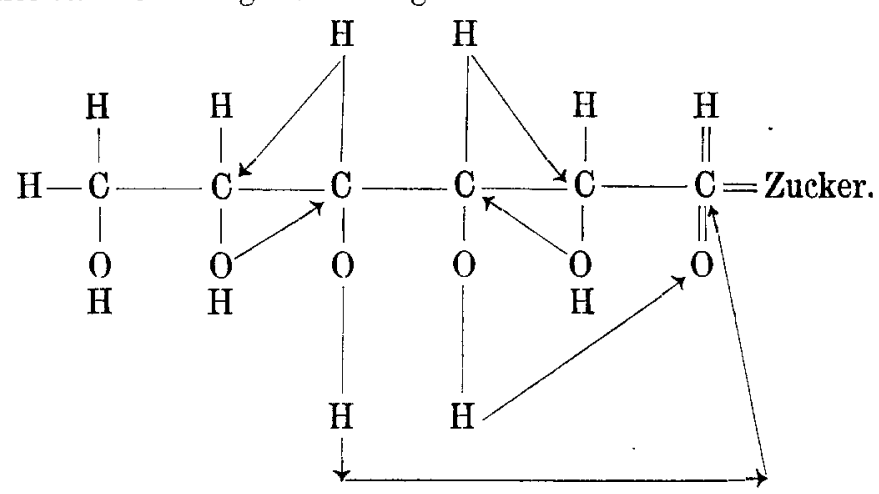

Die Pfeile bezeichnen den Weg, den die einzelnen Atome bei der Gährung durchwandern. So entsteht:<smiles>CCO</smiles>

Alkohol
$\mathrm{CO}_{2} \mathrm{CO}_{2}$

2 Kohlensäuren<smiles>CCO</smiles>

Alkohol

Diese Verschiebungen der Atome, welche einen Zerfall des Zuckermoleküls in vier Brucbstücke bedingen, sind meines Erachtens das Werk der Lebensthätigkeit der Hefe. Den durch Pressen der Hefe erhaltenen Saft, der die Poren des Filters durchsetzt hat, halte 
ich nicht frei von lebendiger Substanz, wenn er auch keine vollkommenen Zellen mehr enthält.

Die sogenannte Zymase des Saftes besteht sicher aus kleinen Fetzchen noch lebendiger Zellsubstanz der Hefe. Die ganze allgemeine Nervenphysiologie ist aufgebaut auf Versuche, die an ausgeschnittenen Stückchen von Nervenfasern ausgeführt wurden, welche Zellsubstanz sind. Denn der Axencylinder ist nur ein ausgezogenes Stück der Substanz der Nervenzelle, welche noth viele Stunden, ja Tage, trotz vielfacher Misshandlungen ibre Lebensfähigkeit behauptet.

Wie also das Zuckermolekül gespalten wird durch Oxydation von $\mathrm{C} \mathrm{zu} \mathrm{CO}_{2}$, so verhält es sich wohl auch bei der Spaltung der langen Kohlenstoffketten der Fettsäuren.

Wie ist nun die Hydroxylirung der durch die Spaltung entstandenen Alkoholradicale zu begreifen? Dass solche Hydroxylirungen im thierischen Stoffwechsel vorkommen, habe ich bewiesen, indem ich bei Digestion lebendigen Leberbreies mit Blut Phenol in Brenzkatechin übergehen sah. Ich stelle mir vor, dass die neben dem Hydroxyl des Phenols stehenden beiden benachbarten Wasserstoffatome zuerst oxydirt werden und als Wasser austreten, so dass die Elemente des Wassers dann die zwei frei gewordenen Valenzen der zwei Kohlenstoffatome ersetzen. Es ist bemerkenswerth, dass Orthostellung eintritt. Also

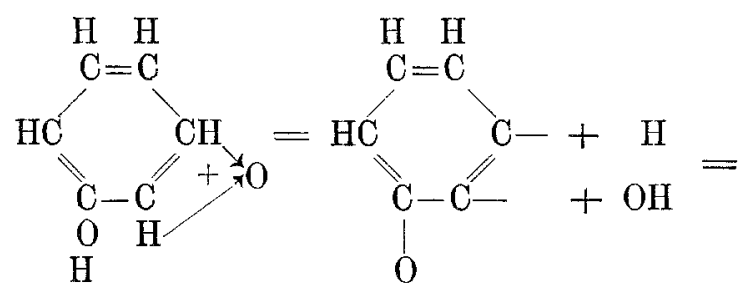

Phenol + Sauerstoff $\mathrm{H}$<smiles></smiles>

Wir werden in der Folge noch ein interessantes Beispiel der Hydroxylirung eines aliphatischen Kohlenwasserstoffs kennen lernen. 
Die in der Fettsäure enthaltene Kette stelle den Anfangszustand I dar:

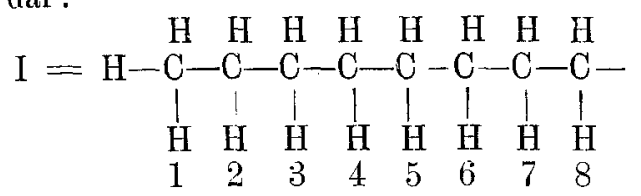

Indem ein D-Atom den Wasserstoff 1 und 2 wegnimmt und die bei 1 und 2 freigewordenen Valenzen durch die Elemente des Wassers ersetzt werden, entsteht die Stufe II:

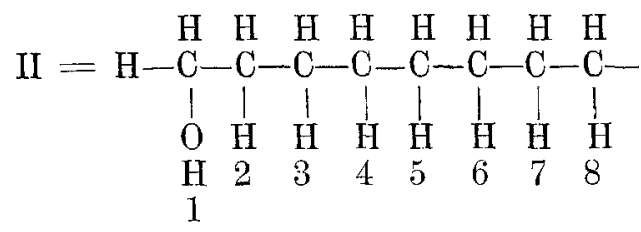

Indem dann in Stufe II Wasserstoff 2 und 3 durch ein 0 weggenommen und die freigewordenen Valenzen wieder durch die Bruchstücke des Wassers ersetzt werden, entsteht (gleichsam Orthostellung) Stufe III:

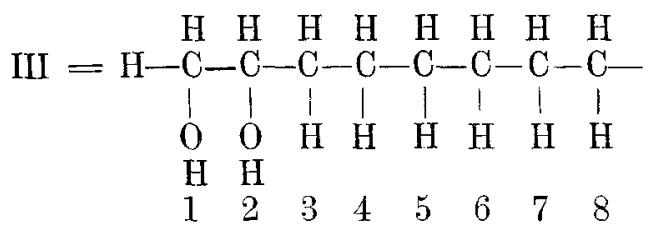

Indem dann in Stufe III Wasserstoff 3 und 4 durch $O$ weggenommen und die freigewordenen Valenzen durch die Bruchstücke des Wassers ersetzt werden, entsteht Stufe IV:

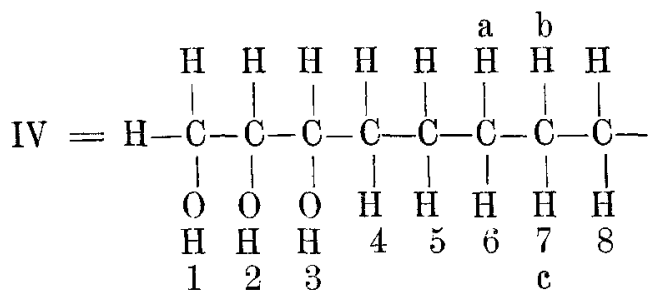

Denken wir uns die Hydroxylirung bis zum C-Atom 5 (inclusive) vorgeschritten, so gelangen wir zu den $\mathrm{C}$-Atomen 6 und 7 , bei denen der Oxydationsprocess sich ändert. Die 2 H-Atome $\mathrm{a}$ und $\mathrm{b}$ am C-Atom 6 und 7 werden durch $O$ fortgenommen, und ein zweites O-Atom verbindet sich mit dem $\mathrm{C}$-Atom 6 , wodurch das neugebildete Zuckermolekül durch die Aldehydgruppe abgeschlossen ist. Das CAtom 7 verbindet sich mit $\mathrm{O}_{2}$ zu Kohlensäure und das am C-Atom 7 
stehende $\mathrm{H}$-Atom $\mathrm{e}$ tritt zum $\mathrm{C}$-Atom 8 , so dass nunmehr genau derselbe Process wie eben beschrieben auf's Neue sich fortsetzen kann.

Desshalb liefert 1 Molekül Stearinsäure oder Oelsäure, weil eine Kette von $18 \mathrm{C}$-Atomen vorliegt: 2 Moleküle Traubenzucker, 2 Moleküle Kohlensäure und 1 Molekül Buttersäure, aus welcher dann ferner die $\beta$-Oxybuttersäure hervorgeht; 1 Molekül Palmitinsäure, die eine Kette von $16 \mathrm{C}$-Atomen besitzt, wird liefern 2 Moleküle Traubenzucker, 2 Moleküle Kohlensäure und 1 Molekül Essigsäure.

Ich erwarte nunmehr den Einwand, dass ich keine Berechtigung mehr hätte, die Zuckerbildung aus Aminosäuren, also aus Bestandtheilen des Eiweissmoleküles, zu leugnen. Denn nach Desamidirung der Monaminsäuren erhalten wir eine Fettsäure. Dass Desamidirung im Organismus vorkommt, folgt daraus, dass nach Baumann ${ }^{1}$ ) Tyrosin

in Hydroparacumarsäure

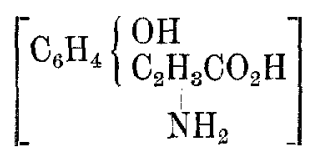

und Oxyphenylessigsäure

$$
\left[\mathrm{C}_{6} \mathrm{H}_{4}\left\{\begin{array}{l}
\mathrm{OH} \\
\mathrm{C}_{2} \mathrm{H}_{4} \mathrm{CO}_{2} \mathrm{H}
\end{array}\right]\right.
$$

$$
\left[\mathrm{C}_{6} \mathrm{H}_{4}\left\{\begin{array}{l}
\mathrm{OH} \\
\mathrm{CH}_{2} \mathrm{CO}_{2} \mathrm{H}
\end{array}\right]\right.
$$

ubergeht, wobei das in der Seitenkette Alanin befindliche $\mathrm{NH}_{2}$ gegen $\mathrm{H}$ umgetauscht wird. Der Vorgang ist eine Reduction. Nach (len Versuchen Blendermann's ${ }^{2}$ ) liefert Tyrosin auch Oxyphenylmilchsäure oder Oxyhydroparacumarsäure:

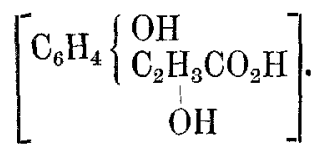

Hier geschieht die Desamidirung durch Hydrolyse. Hierher gehört nach Baumann auch die Oxymandelsäure:

$$
\left[\begin{array}{c}
\mathrm{C}_{6} \mathrm{H}_{4}\left\{\begin{array}{l}
\mathrm{OH} \\
\mathrm{CHCO} \\
\mathrm{OH}
\end{array}\right]
\end{array}\right] .
$$

1) E. Baumann, Zeitschr. f. physiol. Chemie Bd. 4 S. 304. - Berliner Ber. Bd. 12 S. 145 und Bd. 13 S. 279.

2) Blendermann, Zeitschr. f. physiol. Chemie Bd. 6 S. 256. 
Erwähnt werden darf ferner, dass C. Neuberg und L. Langstein ${ }^{1}$ ) hungernde Kaninchen mit Alanin fütterten und dann im Harne grössere Mengen Milchsäure nachweisen konnten, die also wobl dureh desamidirende Hydrolyse aus dem Alanin entstanden war. Wahrscheinlich sind diese Desamidirungen durch die Fäulnissprocesse des Darmes bedingt. Doch will ich desshalb keinen Einwand erheben. Denn auch bei der Fäulniss handelt es sich um die Wirkung lebendiger Zellsubstanz.

Auf Grund der besprochenen Vorstellungen sind nun viele Untersuchungen mit Aminosäuren angestellt, um deren im Organismus sich vollziehende Umprägung in Kohlehydrat zu beweisen. Ueberblickt man die stattliche Reihe der angestellten Versuche mit unbefangenem Auge, so kann es keinem Zweifel unterliegen, dass aus den Aminosäuren, welche Bestandtheile des Eiweissmoleküles sind, keine Kohlehydrate entstehen. Zunächst wären die Versuche $\mathrm{zu}$ beurtheilen, welche mit Leuein (Aminocapronsäure) angestellt wurden, das von Friedrich Müller, dem jetzigen Münchener Kliniker, als Zuckerbildner in erster Linie in das Auge gefasst worden ist.

Schon $\mathrm{Rudolf} \mathrm{Cohn}^{2}$ ) verfütterte Leucin an Kanincben und fand in allen Fällen eine sehr beträchtliche Anhäufung von Glykogen in der Leber des Thieres. Es handelt sich um Steigerungen bis zu mehr als $400 \%$ :

Glykogengehalt der Leber $\quad 1,16 \quad 1,80 \quad$ Controlthier, $4,60 \quad 2,3(?) \quad 2,1 \quad 2,8$ Leucinthier.

Da sollte man doch meinen, die Zuckerbildung aus Leucin sei auf das glänzendste bewiesen. Das ist aber eine arge Täuschung. Denn unter scheinbar gleichen Lebensbedingungen schwankt der Gehalt der Leber um ein Vielfaches, wesshalb zwei Controlthiere, welche R. Cohn anwandte, nicht entfernt genügen. Dazu kommt, dass R. Cohn den Glykogengehalt des übrigen Körpers nicht bestimmt hat. Wie Athanasius) bewies, wächst auch bei der Phosphorvergiftung der Fettgehalt der Leber; aber der Fettgehalt des ganzen Körpers bleibt unverändert. R. Cohn's Versuch beweist also nichts.

1) Neuberg und Langstein, Engelmann's Arch. 1908 Suppl. S. 514.

2) R. Cohn, Zeitschr. f. physiol. Chemie Bd. 28 S. 211-218. 1899.

3) J. Athanasiu, dieses Archiv Bd. 74 S. 511. 1899. 
Dass dies sich so verhält, geht aus einer Arbeit hervor, welche Oscar Simon ${ }^{1}$ ) im Laboratorium von N. Zuntz ausgeführt hat. Er machte Kaninchen durch Vergiftung mit Strychnin glykogenfrei und fütterte sie wiederholt per Schlundsonde mit $15-18 \mathrm{~g}$ Leucin. Weder in den Muskeln noch in der Leber liess sich mit der Pflüger'schen Methode Glykogen nachweisen. Friedrich Kraus ${ }^{2}$ ) hat den Versuch O.Simon's an der Katze wiederholt und bestätigt.

Einen neuen Anstoss erhielt die Frage durch die Vermuthung von Emil Fischer, dass es möglicher Weise die Aminosäuren mit einer Kette von drei Kohlenstoffatomen seien, die zu den Kohlehydraten in verwandtschaftlicher Beziehung stehen. Fin constanter Bestandtheil des Fiweissmolekules ist nuu in der That das Alanin $\left(\mathrm{CH}_{3} \cdot \mathrm{CH} \cdot \mathrm{NH}_{2} \cdot \mathrm{CO}_{2} \mathrm{H}\right)$. C. $\mathrm{Neuberg}$ und Dr. L. Langstein $\left.{ }^{3}\right)$ unternahmen es desshalb, hungernde Kaninchen mit Alanin zu füttern.

Neuberg und Langstein berichten, dass bei ihren Versuchen am Hungerthier das "überraschende" Resultat einer Glykogenanhäufung von 1 bis $2 g$ in der Leber sich herausgestellt habe. "Das Glykogen, das in den Muskeln angehäuft war, kam nicht in "Rechnung." Wie man sieht, ist diese „Arhäufung" noch nicht so gross wie in dem Leucinversuch von Rudolf Cohn, hei dem "Anhäufungen" von 2,3 bis $4,6 \mathrm{~g}$ erzielt wurden, und trotzdem ist dieses nach Neuberg und Langstein mehr als "überraschende" Ergebniss durch Oscar Simon und Friedrich Kraus widerlegt. Was will denn eine Anhäufung von 1 bis $2 \mathrm{~g}$ Glykogen in der Leber besagen, von der man weiss, dass sie bis $19 \%$ Glykogen enthalten kann, und dass die individuellen Schwankungen unter denselben Lebensbedingungen ganz ungeheuer gross sind. Da kann man sich nicht auf zwei Thiere stützen, weil der Zufall eine zu grosse Rolle spielt. Wie man solche Versuche in einer wissenschaftlichen Zeitschrift veröffentlichen kann, ist mir ganz unbegreiflich. Dazu kommt dann, dass weder das Gewicht der Thiere noch der Leber angegeben ist. Denu die erwachsenen gebräuchlichen Kaninchen haben ein Gewicht von ungefähr 1,5 bis 4 Kilo, so dass

1) Oscar Simon, Zeitschr. f. physiol. Chem. Bd. 95 S. 315.1902.

2) Friedrich Kraus, Berliner klin. Wochenschr. 1901 Nr. 1 S. 7.

3) C. Neuberg und L. Langstein, Engelmann's Arch. 1903. Supplementband S. 514 . 
Ueb. die im thier. Körper sich vollziehende Bildung von Zucker etc.

bei $3 \%$ Lebergewicht die Leber ungefähr 45 bis $120 \mathrm{~g}$ wiegt. Wenn die Leber nur $45 \mathrm{~g}$ gewogen hätte, so würde sie $2,2 \%$ bis $4,4 \%$, wenn sie $120 \mathrm{~g}$ gewogen hätte, $0,8 \%$ Glykogen enthalten haben. Also eine Leber, die 0,8 bis $4,4 \%$ Glykogen enthält, soll eine "Anhäufung" von Glykogen beweisen, sogar falls die Kaninchen grosse Thiere waren, eine Leber mit $0,8 \%$ Glykogen, obwohl man weiss, dass die Leber 20 Mal so viel Glykogen enthalten kann. Controlversuche scheinen Neuberg und Langstein überhaupt nicht gemacht zu haben, denn kein Wort ist die Rede von dem Glykogengehalt der Controlthiere. Das Glykogen des Gesammtkörpers ist auch nicht bestimmt worden. Es ist also die Mangelhaftigkeit dieses Versuches über die Maassen gross.

Friedrich $\mathrm{Kraus,}$, einer der eifrigsten Vertreter der Zuckerbildung aus Eiweiss, hat die Frage, ob aus Alanin im Thierkörper Glykogen entstehen kann, auf's Neue in Angriff genommen.

Zwei Gruppen Katzen wurden in gleicher Weise gefüttert; die eine Gruppe getödtet und der Glykogengehalt des ganzen Körpers bestimmt; die andere Gruppe erhielt keine Nahrung, aber Phloridzin und an einigen Tagen Alanin oder Leucin. Folgende Tabelle zeigt nach Kraus die Ergebnisse:

$100 \mathrm{~g}$ Thier enthalten Glykogen in Gramm. Das Glykogen ist in Traubenzucker umgerechnet.

\begin{tabular}{|c|c|c|c|c|c|}
\hline $\begin{array}{l}\text { Controlthiere ge- } \\
\text { tödtet beim Beginn } \\
\text { der Versuchsreihen }\end{array}$ & \multicolumn{5}{|c|}{$\begin{array}{l}\text { Versuchsthiere für die Phloretin-Hungerversuche. } \\
\text { Angegeben sind die im Harn ausgeschiedenen Zucker- } \\
\text { mengen + dem Restglykogen }\end{array}$} \\
\hline I. $0,2637 \mathrm{~g}$ & I. $0,5887 \mathrm{~g}$ & . . . & $8 \mathrm{t}$ & & \\
\hline II. $0,3773 \mathrm{~g}$ & II. $1,2282 \mathrm{~g}$ & tägl. $5 g$ & 6 & & \\
\hline III. $0,2414 \mathrm{~g}$ & III. $0,7724 \mathrm{~g}$ & Alanin & & & \\
\hline IV. $0,4900 \mathrm{~g}$ & IV. $0,3272 \mathrm{~g}$ & $\begin{array}{l}\text { tägl. } 1 \mathrm{~g} \\
\text { Leucin }\end{array}$ & 5 & $"$ & $"$ \\
\hline V. $0,1985 \mathrm{~g}$ & V. $0,4356 \mathrm{~g}$. &.$\quad \cdot$ & .5 & $n$ & $\because$ \\
\hline
\end{tabular}

Wenn man die Alaninversuche (II und III) mit den übrigen vergleicht, so ergibt sich eine kleine Steigerung des Glykogengehaltes, die doch wahrscheinlich durch Zufall bedingt ist. Wäre es aber auch kein Zufall, so bleibt doch zu bedenken, dass von den Controlthieren nur das Glykogen, nicht die Gesammtmenge der Kohlehydrate bekannt ist, und dass der Zucker noch aus Glycerin oder einer anderen Quelle stammen könnte. 
Beim Leucinversuch Rudolf Cohn's sind die Unterschiede noch viel grösser, und es ist doch nur Zufall:

Ohne Leucin . . . 1,16-1,80

Mit Leucin . . $4,60-2,3-2,1-2,8\}$ glykogen.

Obwohl nun Friedrich $\mathrm{Kraus}^{1}$ ) noch einen Alaninversuch an einer Katze angestellt, der, wie er selbst zugibt, ein negatives Ergebniss hatte, sucht er sich über die klaren negativen Leucinversuche durch eigenthümliche Betrachtungen hinwegzuhelfen. Friedrich $\mathrm{Kraus}$ bespricht seinen negativ ausgefallenen Alaninversuch also: „Das Resultat war in diesem letzteren Falle jedoch ein negatives. „Ohne das verschiedene Verhalten erklären zu können (vielleicht "rührt es davon her, dass ich das active, aus Seide herstellbare "Präparat nicht verwendete), halte irh doch das in den zwei früher "erwähnten Versuchen gewonnene Ergebniss für bedeutsam."

Dass also auch wohl bei den negativen Leucinversuchen nicht die richtige Modification zur Fütterung verwandt wurde, wird von Friedrich Kraus ${ }^{1}$ ) noch in besonders eingehender Weise folgendermaassen zu begrunden gesucht:

„Jedenfalls lehren Versuche, dass es, biologisch und chemisch "betrachtet, nicht widersinnig ist, die zuckerbildende Componente "des Eiweiss, sei es unter normalen oder bloss unter pathologischen „Bedingungen, auch in der Reihe derjenigen zu den Aminosäuren ge"hörigen Spaltungsproducte zu suchen, welche selbst keine Kohle"bydratnatur besitzen. Den Ergebnissen solcher Versuche wohnt "eine grössere Wahrscheiulichkeit inne, weil sie Aufschluss gewähren "können nicht bloss über eventuelle chemische Vorstufen des ge"bildeten Zuckers, sondern auch darüber, wie sich die Zellen der "Organismen angepasst haben an eine bestimmte Länge der dar„gebotenen Kohlenstoffketten, sowie an die intime Gliederung der "dem Intermediärstoffwechsel verfallenden Moleküle, z. B. an deren "Enantiomorphie. So haben sich interessante Verschiedenheiten "herausgestellt in Bezug auf die Gährungsfähigkeit der einzelnen "Monosaccharide: die Eigenschaft der raschen Vergährbarkeit kommt "bloss den Triosen, Hexosen und Nonosen zu, den Pentosen z. B. "nicht. Aber unter den vielen gegenwärtig bekannten Hexosen sind "wiederum niclit alle vergährbar, es besteht ein wichtiger Unterschied "zwischen der $d$-Glycose und $d$-Fructose und ihren optischen Anti„poden. Die Mikroorganismen wissen eben, sit venia verbo, wohl

1) Friedrich Kraus, Berliner klin. Wochenschr. 1904 Nr. 1 S. 8. 
„zu unterscheiden zwischen enantiomorphen Configurationen. Dienen "sie uns doch auch zur Abscheidung von optisch activen Modificationen „aus racemischen solchen; Penicillium glaucum z. B. verschmäht "das Linkstartrat und vermehrt sich auf Kosten der Rechtsweinsäure. „Hinwiederum gibt es Zellen, z. B. die sekretorischen Nierenelemente "höherer Thiere, welche die racemische Form leichter ausscheiden „als jede ihrer Componenten. Wie Brion gezeigt, ist der Harn "nach Verabreichung von Traubensäure in der Regel inactiv, obwohl "die einzelnen Componenten nicht im gleichen Grade im Organismus "versehwinden. Wenn wir, immer in ähnlicher Weise stereophysio"logisch vorgehend, die Stoffwechselversuche auch mit den Aminosäuren. "bei Diabetikern fortsetzen, werden wir vielleicht weiter kommen, "als wenn wir consequent bestrebt sind, Kohlehydrat von Kohle"hydrat herzuleiten und von nichts Anderem, wo doch der Begriff "Kohlehydrat verschiedenen Wandlungen unterworfen gewesen ist und "sein wird. Auch verliert es gerade so alles Räthselhafte, wenn zwar "Glycerin und Alanin, aber z. B. nicht Pentosen Glykogenbildner sind."

Wir erkennen hiernach, wie man sich nach Friedrich Kraus das negative Ergebniss der Leucinversuche vom Standpunkt einer höheren Warte vorzustellen hat. Das gefütterte Leucin war eben in allen Fällen nicht die richtige Art oder Configuration des Leucins. Die thierischen Zellen "wissen eben", wie Friedrich Kraus belehrend spricht, "wohl zu unterseheiden zwischen der richtigen "Configuration des Leucins und der unrichtigen, welche leider immer zufällig gefüttert worden ist. Eines nur hat Friedrich Kraus bei seinem Gedankenflug ausser Acht gelassen.

Es sollte doch durch den Beweis der Zuckerbildung aus Leucin die Zuckerbildung aus Eiweiss hewiesen werden. Also wird doch wohl im Casein, das 50\% Leucin enthalten soll, die richtige Configuration für die Zuckerbildung enthalten sein. Nun beweisen aber mit der grössten Sicherheit die umfassenden Fütterungsversuche von B. Schöndorff, dass bei Fröschen aus Casë̈n auch nicht die Spur von Kohlehydrat im Thierkörper entsteht. Blumenthal und Wohlgemuth haben diese Thatsache bestätigt. Hier handelt es sich um Kaltblüter, was ich nicht für wesentlich halte. Aber es liegen Versuche an Warmblütern von E. Külz und Anderen vor, bei denen nach Caseïnfütterung keine Glykogenbildung nachgewiesen werden konnte. Ich ${ }^{1}$ ) habe alle systematischen Fütterungsversuche

1) E. Pflüger, dieses Arch. Bd. 96. S 227. 1909. 
nit Eiweiss in meiner Monographie des Glykogenes auf das eingehendste bearbeitet und bewiesen, dass nirgends von einer Glykogenbildung die Rede sein konnte. In dem gefütterten Eiweiss mussten doch die echten Configurationen der Aminosäuren sein. Es ist also gewiss, die Aminosäuren erzeugen keinen Zucker.

Bemerkt mag endlich noch werden, dass Blumenthal ${ }^{1}$ ) in der Sitzung der med. Gesellschaft in Berlin bei Besprechung von Kraus' Vortrag im Hinblick auf die Versuche von Neuberg, Langstein und $\mathrm{Kraus}$ hervorhob, "dass hier zum ersten Male ein wirklicher "Beweis dafür vorliegt, dass aus einer Aminosäure Zucker gebildet "werden kann." Das ist derselbe Blumenthal ${ }^{2}$ ), der mit Wohlgemuth zwar nicht den ersten, aber den zweiten Beweis erbracht hat, dass aus Caseïn kein Glykogen entsteht, obwohl das Caseïn Alanin und Leucin in Masse enthält.

Die Berliner Forscher, deren Versuche ich soeben besprochen habe, gelangten zu der Vorstellung, dass die Aminosäuren desamidirt werden müssten, um in Zucker übergehen zu können, Dann würde der Zucker aus Fettsäuren entstehen. Es würde aus Leucin Capronsäure, aus Alanin Propionsäure hervorgehen. Man müsste also fragen, wie es denn mit der Zuckerbildung steht, wenn man statt Leucin die Capronsäure, statt Alanin die Propionsäure füttert. Diese und analoge Versuche sind bereits 1903 von Dr. Leo Schwarz ausgeführt.

Wenn ich aus der wichtigen Arbeit das Wesentliche, was hier in Betracht kommt, hervorhebe, so handelt es sich um den Nachweis von Stoffen, welche bei Verfütterung von Fettsäure an Diabetiker in den Harn übergehen. Es ist hierbei kaum ein Zweifel möglich, dass die Fettsäuren die Muttersubstanzen dieser Stoffe sind.

Das wichtigste Ergebniss liegt in dem Nachweise, dass die in der Nahrung der Diabetiker zugeführten Fettsäuren als "Acetonkörper “ im Harn wieder erscheinen. Geelmuyden ${ }^{3}$ ) hat die zusammengehörige Gruppe der Oxybuttersäure, der Acetessigsäure und des Acetons als "Acetonkörper" zu bezeichnen vorgeschlagen. Es hat sich nun durch die Untersuchungen von Weintraud ${ }^{4}$ ), Rosen-

1) Blumenthal, Berliner klin. Wochenschr. Nr. 3 S. 71.1904.

2) F. Blumenthal und J. Wohlgemuth, Berliner klin. Wochenschr. Nr 15 S. 391. 1901.

3) Geelmuyden, Zeitschr. f. physiol. Chem. Bd. 23 S. 431.1897.

4) Weintraud, Arch. f. exper. Pathol. u. Pharmak. Bd. 34 S. 169. 
feld ${ }^{1}$ ), Hirschfeld ${ }^{2}$ ) und Geelmuyden ${ }^{3}$ ) herausgestellt, dass das Erscheinen der Acetonkörper im Harn wesentlich herabgesetzt, ja beseitigt wird, wenn neben den Fettsäuren viel Kohlehydrate oder auch viel Eiweiss als Nahrung gereicht wird. Das ist dje Bedingung, welche den Fettstoffwechsel herabsetzt. In Uebereinstimmung hiermit ist, dass bei Entziehung der Kohlehydrate und des Eiweisses die Fütterung von Fettsäuren sogar beim Gesunden die Ausscheidung der Acetonkörper im Harne zur Folge hat. Dies zeigt, dass die Fettsäuren die Muttersubstanz der Acetonkörper sind. Ihre reichliche Entstehung setzt voraus, dass der Stoffwechsel sich vorzugsweise auf Kosten von Fett vollzieht.

Wie durch die Untersuchungen von Le o Schwartz bewiesen worden ist, sind es wesentlich die Fettsäuren von niederem Molekulargewicht, welche als Muttersubstanzen der Acetonkörper zu betrachten sind, nämlich: Capronsäure, in hervorragender Weise die Valeriansäure und die Buttersäure; nicht die Propionsäure ${ }^{4}$ ). Die Fettsäuren von hohem Molekulargewicht, wie die Stearinsäure, Palmitinsäure, Oelsäure, wirken so schwach, dass es lange zweifelhaft war, ob sie überhaupt zu der Acetongruppe in einer Beziehung stehen. Nach den neuen Untersuchungen von Leo Schwarz scheint es aber, als ob sie doch unter Umständen einen geringen Einfluss ausüben.

Die Mechanik der Verwandlung der Fettsäure in Acetonkörper ist von dem höchsten Interesse, wesshalb ich für einen Augenblick darauf eingehe.

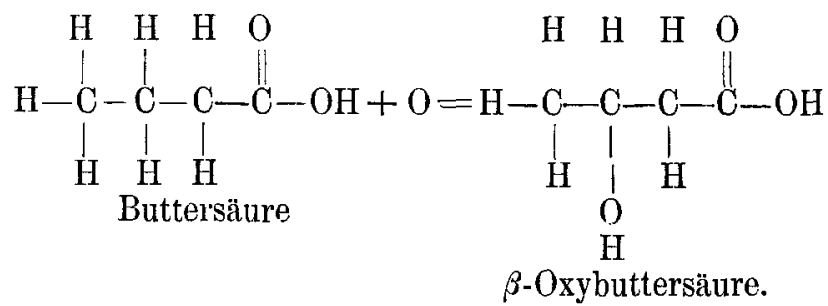

Hier haben wir den werthvollen Beweis, dass der thierische Stoffwechsel auch ein zur aliphatischen Reihe gehöriges Alkyl hydroxyliren kann. Ich hatte ja bereits den gleichen Vorgang an

1) Rosenfeld, Centralbl. f. innere Med. 1895 Nr. 51.

2) Hirschfeld, Zeitschr. f. klin. Med. Bd. 28 S. 176. 1895.

3) Geelmugden, Zeitschr. f. physiol. Chem. Bd. 23 S. 473.1897.

4) Leo Schwarz, a. a. O. S. 252. 
einem aromatischen Kohlenwasserstoff: die Ueberführung des Phenols in Brenzkatechin erwähnt. Ich bin der Ansicht, dass die von mir angenommene Mechanik der cbemischen Reaction auch hier angenommen werden darf. Dadurch ist eine festere Basis für die Vorstellung der Verwandlung der höheren Fettsäuren in Zucker gegeben.

Der Uebergang der $\beta$-Oxybuttersäure in Acetessigsäure

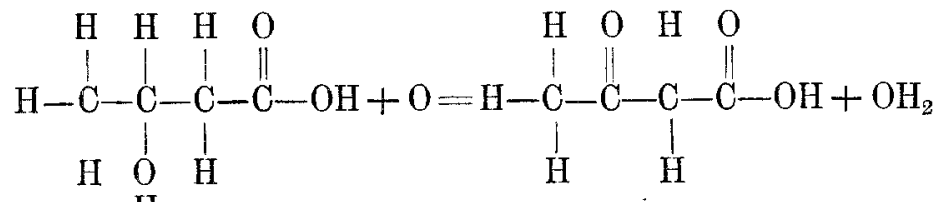

$\beta$-Oxybuttersäure

Acetessigsäure

vollzieht sich wesentlich, wie es bei der Oxydation des Glycerins zu Glycerinketon geschieht.

Der Uebergang der Acetessigsäure in Aceton ist durch eine Abspaltung von $\mathrm{CO}_{2}$ bedingt:<smiles>CC(C)CCC(=O)CC(C)C(=O)O</smiles>

Es ist ein Vorgang ganz ähnlich wie bei dem Abbau des Thyrosins im Darme: aus der Hydroparacumarsäure entsteht das Paraethylphenol, aus der Oxyphenylessigsäure das Parakresol, aus der Paraoxybenzoësäure das Phenol.

Ich habe mir nun die Protokolle von Leo Schwarz genau angesehen. Da ist nirgends die Spur einer Vermehrung des Harnzuckers nach Einnahme der genannten Fettsäuren zu bemerken.

Das Ergebniss bei Fütterung von Propionsäure an einem schweren Diabetiker war:

\begin{tabular}{|c|c|c|}
\hline $\begin{array}{l}\text { Beobachtungs- } \\
\text { tag }\end{array}$ & $\mathrm{Zul}$ a ge & Zucker in $\mathrm{g}$ \\
\hline I & - & 98 \\
\hline II & $100 \mathrm{~g}$ Oelsäure & 86 \\
\hline III & $30 \mathrm{~g}$ propionsaures Natron & 101 \\
\hline
\end{tabular}

Die allerdings vorhandene kleine Steigerung der Zuckerausscheidung fällt in die Breite der. Beobachtungsfehler. 
Nur die Acetonkörper sind also in oft sehr bedeutender Menge vermehrt und bezeugen, dass an eine Entstehung von Zucker aus den niederen Fettsäuren nicht zu denken ist.

Ich war ja schon oben zu dieser Anschauung gelangt, der zu Folge nur Kohlenstoffketten zu Zucker verarbeitet werden, die wenigstens 6 oder 7 Methylengruppen enthalten.

Meine Darstellung über die Zuckerbildung aus Fett führt uns eine chemische Reaction vor, welche, in immer "nahezu derselben Weise verlaufend, die Entstehung grosser Zuckermengen aus Fett begreiflich macht. Die Hypothese der Zuckerbildung aus Eiweiss muss die Annahme zulassen, dass die allerverschiedenartigsten Atomcomplexe rom Organismus in Zucker umgeprägt werden können. Die Hypothese der Zuckerbildung aus Eiweiss steht im Widerspruch mit allen guten experimentellen Thatsachen, welche bezeugen, dass Eiweiss sich niemals im lebendigen Körper in Kohlehydrat verwandeln kann. Darum ziehe ich, wenn es erwiesen ist, dass die präformirten Kohlehydrate zur Erklärung der diabetischen Zuckerausscheidung nicht genügen, die Annahme der Zuckerbildung aus Fett unbedingt vor.

Es ist gerecht, nochmals hervorzuheben, dass Theodor Rumpf ${ }^{1}$ ) auf Grund seiner wichtigen Versuche über Phloridzindiabetes bereits die hierbei ausgeschiedenen grossen Zuckermengen aus Fett und nicht aus Eiweiss abgeleitet hat.

Einen Einwand möchte ich endlich noch besprechen, den Mancher daraus ableiten könnte, dass nach den Versuchen von Leo Schwarz die Zufuhr von Fettstoffen beim Diabetiker allerdings zu einer Oxydation und Verarbeitung derselben führt, obwohl ich oben hervorhob, dass das Nahrungsfett keine Steigerung der Oxydationsprocesse bedingt und unangegriffen bleibt. Man muss bedenken, dass die von Leo Schwarz gereichten Fettstoffe eben kein Fett sind, sondern nur Oxydations- und Spaltungsproducte wie auch das Glycerin. Wie das Glycerin sind auch diese oxydirbar, die Fette aber nicht. Fs ist hierbei von grossem Gewicht, dass die höheren mit der Nahrung zugeführten Fettsäuren, die ja den Hauptbestandtheil der Fette bilden, auch beim Diabetiker sich nach Leo Schwarz kaum am Stoffwechsel betheiligen.

1) Dr. Hartogh und O. Schumm, Arch. f. exper. Pathol. u. Pharmak. Bd. 45 S. 11. 
Wenn sie das dennoch in geringem Grade thun, so hat man zu bedenken, dass die Nichtoxydirbarkeit des mit der Nahrung zugeführten Fettes nicht strictissimo sensu zu nehmen ist. Denn Carl Voit hat den Beweis geliefert, dass das neben Eiweiss in der Nahrung zugeführte Fett eine geringe Ersparniss an Eiweiss bedingt.

Diese Thatsache ist merkwürdig genug. Wenn das Fett im normalen Lauf dès Stoffwechsels von seinen Lagerstätten durch das Blut nach den Organen abströmt, wo es weiter verarbeitet werden soll, so lässt sich denken, dass die unendlich feine Emulsion des resorbirten Nahrungsfettes den nach den Werkstätten der Verarbeitung gerichteten Fettstrom ein wenig ansehwellt und so eine geringe Steigerung der Oxydation des Fettes bedingt.

Hierdurch glaube ich das besprochene Berdenken beseitigt zu haben.

Wir sind nunmehr ansreichend vorbereitet zur Widerlegung einer Begründung, welche Professor Nathan $\mathrm{Zuntz}^{1}$ ) am 6. Januar dieses Jahres in der Sitzung der Berliner medicinischen Gesellschaft für die Zuckerbildung aus Eiweiss vorgetragen hat.

N. Zuntz erinnert daran, dass der respiratorische Quotient der Kohlehydrate $=1$, der des Eiweiss $=0,81$, der der Fette $=0,69$ sei. Folglich muss unter normalen Verhältnissen der respiratorische Quotient zwischen 0,69 und 1 liegen. N. Zuntz hat aber beim Phloridzindiabetes den respiratorischen Quotienten auf 0,69 , ja, unter 0,63 sinken sehen. Das ist nur begreiflich, wenn ein Theil des eingeathmeten Sauerstoffs irgendwie verschwindet. Wäre der ausgeschiedene Zucker aus präformirtem Kohlehydrat abzuleiten, so wäre nach Zuntz nicht abzusehen, warum der respiratorische Quotient unter den niedrigsten Normalwerth, 0,69 , sinkt. Dass der respiratorische Quotient unter 0,69 sinken, wenn es sich nicht um Diabetes handelt, und über 1 steigen kann, wo es sich nicht um Fettbildung aus Kohlehydrat handelt, ist gewiss. Da nun Manches dafür spricht, dass beim Diabetes eine Schwächung der Oxydationsprocesse vorliegt und diese im Thierkörper wohl so ablaufen, dass im Kohlenwasserstoff in einer ersten Phase der Wasserstoff und in einer zweiten erst der Kohlenstoff vom Sauerstoff in Beschlag genommen, aber noch nicht oxydirt wird, so können $\mathrm{Zu}$ stände vorkommen, bei denen im Eiweiss 0 gebunden ist, wie in

1) Prof. Natan Zuntz, Berliner klin. Wochenschr. 1904 Nr. 3 S. 70. 


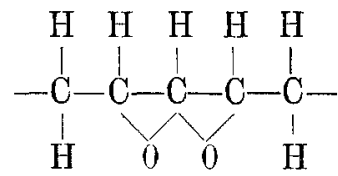

"Stellt man sich aber vor," sagt $\mathrm{Zuntz}$, "dass der verschwindende Sauerstoff verbraucht wird, um aus den sauerstoffarmen Bestandtheilen des Eiweiss Zucker zu bilden, so versteht man die ungeheure Senkung des respiratorischen Quotienten." Zuntz erklärt, dass er seine Versuche noch nicht für hinlänglich beweiskräftig halte. Es ist aber ganz einleuchtend, dass der von mir dargelegte Modus der. Zuckerbildung aus Fett die Senkung des respiratorischen Quotienten weit unter 0,69 auch erklärt. Die angeführte Bedeutung des von $\mathrm{Zunt} z$ bei Diabetes beobachteten niedrigen Werthes des respiratorischen Quotienten kann also nicht für die Zuckerbildung aus Eiweiss in Anschlag gebracht werden.

Die von mir und J. A thanasiu nachgewiesene Aufspeicherung von Sauerstoff im Körper der Frösche steht vielleicht auch zu der von mir entdeckten Thatsache in wesentlicher Beziehung, dass während des Winterschlafes das Fett fast verschwindet, während der Glykogenbestand fast unverändert bleibt, und dass nach Couvreur ${ }^{1}$ ) in der Seidenraupe zur Zeit des Verpuppens das Glykogen sich auf Kosten des Fettes vermehrt. Die übrigen von Zuntz gegen mich beigebrachten Gründe und Bezugnahmen auf die in seinem Laboratorium ausgeführten Arbeiten sind bereits in meiner Monographie des Glykogenes widerlegt und in seinem Vortrag todtgeschwiegen.

Es ist nothwendig, noch eine Betrachtung zu beurtheilen, welche Friedrich Kraus gegen die Zuckerbildung aus Fett und für die aus Eiweiss geltend zu machen sucht. Fr sagt ${ }^{2}$ ): "Bei Menschen, "welche an Diabetes der schweren Form leiden, wird aber häufig "der Fettbestand des Körpers ein so geringer, dass, wenn dieselben "trotzdem bei ausschliesslicher Eiweissdiät fortgesetzt reichliche "Zuckermengen verlieren, die Annahme der Entstehung aus Eiweiss „unmittelbar eine gewisse Wahrscheinlichkeit gewinnt. Auch wir „endlich sind ja im Stande, den Werth einer ohne unser Zuthun ge"stalteten, einfach als complexe Wirklichkeit beobachteten Natur"erscheinung gegen denjenigen einer experimentellen Beweisführung:

1) Couvreur, Compt. rend. Soc. biol. 47.

2) Friedrich Kraus, Berliner klin. Wochenschr. 1904 S. 8. 
„abzuschätzen." Wenn jemals der vornehme Stolz des Klinikers dem Physiologen gegenüber gar nicht angebracht war, so gilt dies für die mitgetheilten Worte von Friedrich Kraus. Hätte er so viele Hunde wie ich auf ihren Fettgehalt durch Extraction mit Aether untersucht und sich nicht damit begnügt, "die als complexe Wirk"lichkeit sich darstellende Naturerscheinung" des Hundes auf ihren Fettgehalt mit dem überlegenen Auge des Klinikers abzuschätzen, so würde er wissen, dass zuweilen Hunde vorkommen, die ausserordentlich mager aussehen und trotzdem sehr reich an Fett sind. Vor einiger Zeit erhielten wir einen Hund, der ein wahres Bild des Jammers war und den Don Quixote an Magerkeit noch übertraf, weil überall seine Knochen hervorragten. Trotzden waren die Muskeln so reich an Fett, dass sie eine weissliche Farbe besassen und bei der Analyse ungewöhnlich grossen Fettgehalt ergaben. Das überlegene klinische Auge von Friedrich Kraus hätte hier sicher die „complexe Wirklichkeit der Naturerscheinung" dieses Huniles doch nicht richtig beurtheilt.

Nachdem ich die Zuckerbildung aus Fett erklärt habe, bleibt mir noch einer der allerwichtigsten Punkte des thierischen Stoffwechsels zu betrachten.

Wenn man bedenkt, dass das neutrale Fett, wie es in den thierischen Geweben vorkommt, nach meinen Untersuchungen vollkommen indifferent gegen Sauerstoff ist, falls man die Wirkung von Fermenten ausschliesst, entsteht die Frage, wie es ermöglicht wird, dass das Fett sich im Organismus doch verhältnissmässig leicht oxydirt. Da liegt es dann nahe, zu denken, dass der tiefere Sinn der Verwandlung des Fettes in Zucker darin besteht, aus einer nicht oxydablen Substanz, dem Fett, eine oxydable, nämlich den Zucker, zu erzeugen. Ueber den Zucker geht der Weg zur vollen Oxydation der Fette.

Das würde mit anderen Worten besagen, dass es sich bei der thierischen Oxydation wesentlich nur um zwei Stoffe handelt: Eiweiss und Zucker. Also jede Bedingung, welche die Oxydation des Zuckers unmöglich macht, hebt zugleich die Oxydation der Fette a uf. Daraus folgt ferner, dass, wenn durch irgend eine Störung die Oxydation des Zuckers geschwächt ist, nothwendig die Oxydation der Eiweisstoffe zunehmen muss. Das ist wahrscheinlich eine der hervorragendsten Ursachen, dass bei den Diabetikern mit der Schwere der Krankheit die Stickstoffausscheidung zunimmt. Sie 
ist es gerade, welche die Kliniker so lange in die Irre geführt hat und sie zu dem Glauben drängte, dass der Zucker aus Eiweiss entstehe.

Es wäre jetzt gerade von ausserordentlicher Bedeutung, wenn man sicher wüsste, ob im Diabetes die Oxydation des Zuckers herabgesetzt ist. Dass Zufuhr von Kohlehydrat beim Diabetiker den respiratorischen Quotienten nicht steigert, hat vielleicht seinen Grund darin, dass der Verbrauch des Zuckers die Neubildung aus Fett veranlasst.

Dass viele, vielleicht alle Diabetesarten durch eine Ueberproduction an Zucker bedingt sind, unterliegt keinem Zweifel. Denn die nach Reizung des Vagus oder anderer Nerven eintretende Glykosurie hat diesen Grund. Der Zucker wird in diesen Fällen in so grosser Menge in das Blut ergossen, dass die Organe nicht schnell genug. denselben zu oxydiren oder in Glykogen umzuprägen im Stande sind. Es könnte aber doch sein, dass die Zellen, deren Leistung in der Verarbeitung so grosser Zuckermengen zur Oxydation besteht, ermüden und in einen lähmungsartigen Zustand verfallen, so dass mit der Vermehrung der Ueberproduction eine immer grössere Schwächung der Oxydationsarbeit der Zellsubstanz sich nothwendig verknüpfte. Es werden dann diejenigen durch die Zuckerbildung aus Fett entstandenen Producte wie die Oxybuttersäure auch schwerer zu Acetessigsäure oxydirt und das Aceton als solches ausgeschieden werden. Je mehr die lebendige Zellsubstanz durch die vicariirende Oxydation schwindet, desto weniger ist die Möglichkeit zur Verarbeitung des Zuckers gegeben, so dass der allgemeine Verfall verständlich wird.

\section{\$ 7. Folgerungen für die Lehre vom Diabetes mellitus.}

Ich habe oft daran gedacht, wie es kommt, dass die Zufuhr einer ungenügenden Menge von Nahrungseiweiss, wodurch ein Abschmelzen und Verbrauch lebendiger Zellsubstanz bedingt ist, sofort eine so mächtige Steigerung der Oxydation der Fette und Kohlehydrate veranlasst, dass hierdurch die Schädigung der lebendigen Zellsubstanz, die gleichbedeutend mit verminderter Leistungsfähigkeit ist, fast ganz beseitigt wird. Wenn ich hier meinem Gesetz ${ }^{1}$ ) der teleologischen Mechanik oder Selbststeuerung folge, sehe ich, dass die nothleidende Substanz sich selbst hilft. Der Sauerstoffmangel der Gewebe, sowie die übergrosse Kohlensäurespannung derselben reizen

1) E. Pflüger, dieses Arch. Bd. 15 S. 57. 1877. 
die Nerven zur Athmung. Die fehlende Nahrung der Zellsubstanz erregt deren Nerven und erzeugt das Gefühl des Hungers, das fehlende Wasser den Durst, und beide Erregungen beseitigen die Noth durch Aufnahme von Nahrung und Wasser. Wenn es sich aber um Mangel an Nahrungseiweiss handelt, müssen die Nerven der nothleidenden Zellsubstanz, welche auch als Eiweisssubstanz geschädigt sind, in Erregung gerathen und reflectorisch auf die Organe wirken, welehe dem Nahrungsmangel abhelfen können. Das ist für die Kohlehydrate keine Hypothese, weil die reflectorisch veranlasste Zuckerbildung der Leber durch das Experiment erwiesen ist. Nur die Deutung dieser Thatsache habe ich zuerst gegeben. Liegt es nun nicht nahe, anzunehmen, dass diese die Zuckerbildung veranlassende Reflexwirkung des Nervensystems sich nicht bloss auf die Leber und ihr Glykogen, sondern auf alle Organe erstreckt, durch deren Zellen Zuckerbildung veranlasst werden kann? Desshalb ist die Annahme berechtigt, der zu Folge auch die das Fett in Zucker umprägenden Zellen oder die "lipotrophen" Organe unter die Herrschaft des Nervensystems gestellt sind.

Man muss die Möglichkeit im Auge behalten, dass das "Zuckercentrum" für die "lipotrophen" und "glykogenotrophen" Organe nicht dasselbe ist. Darum könnte die Leber doch das Organ sein, welches die Fähigkeit besitzt, nicht bloss Glykogen, sondern auch Fett in Zucker umzuprägen. Die Fähigkeiten der Leber sind sehr vielseitige. Sie verhält sich wie eine Spieldose, welche je nach der Einstellung viele Melodien spielen kann. Desshalb ist es denkbar, dass die eine Nervenart die Umprägung des Fettes in Zucker, die ancere aber die des Glykogenes in Zucker veranlasst.

Hiermit sind wir vorbereitet, die Natur des durch Ausrottung des Pankreas erzeugten Diabetes, der für die Auffassung des Kohlehydratstoffwechsels so bedeutungsvoll geworden ist, noch eingehender $\mathrm{zu}$ erforschen.

Die zwei grossen gegen mich gerichteten Arbeiten $\mathrm{L} u$ thje's, welche oben besprochen wurden, stützen sich auf Versuche an Hunden, denen das ganze Pankreas in einer Sitzung exstirpirt worden war. Die Exstirpation ist, wie es scheint, immer nicht von Lüthje, sondern theils in Greifswald von Dr. Eden, theils in Tübingen von Prof. Küttner ausgeführt.

Die zwei Abhandlungen enthalten nämlich meist ältere, schon veröffentlichte Versuche. Es sind also alle Pankreasexstirpationen 
von Chirurgen und zwar von ausgezeichneten Meistern ausgeführt. Damit hängt es denn wohl zusammen, dass die Hunde öfter so sehr lange die Entfernung des Pankreas überleben. Das Allerauffallendste war mir aber, dass mehrere Fälle vorkommen, bei denen nur in den ersten Tagen nach der Exstirpation des Pankreas ein schwacher Diabetes vorhanden ist, der allmählich sehr stark abnimmt, ja vollkommen verschwindet, obwohl aus dem Versuche selbst hervorgeht, dass das Thier sehr viel zuckerbildenden Stoff enthält. Ein Hund, der das ganze Pankreas nicht mehr besitzt, ist zuckerfrei; er hat also auch normalen Zuckergehalt des Blutes. Das Thier hat also keinen Diabetes.

Ich gebe folgende Belege zuerst aus der Arbeit Lüthje's, welche von der Zuckerbildung aus Eiweiss handelt.

Versuch I. Nach der Exstirpation des Pankreas sinkt bei Nahrungsentziehung die 24 stündige Zuckerausscheidung vom 29. Mai bis 22 . Juni von $\mathbf{2 3 , 8 5}$ anf $\mathbf{5}, \mathbf{2} \mathbf{g}$. Anfangsgewicht des Thieres $13 \mathrm{Kilo.}$

Versuch II bezieht sich auf Pankreasdiabetes bei Fütterung mit Pferdefleisch. Aus später anzugebenden Gründen fällt die Betrachtung der Zuckerausscheidung hier aus.

Versuch.III. Nach der Exstirpation des Pankreas bei einem Hunde von $16,3 \mathrm{Kil} 0$ sank die 24 stündige Zuckerausscheidung von 48,02 auf 12 g bei Nahrungsentziehung.

Versuch IV. Bei einem Hunde von anfänglich $6,9 \mathrm{Kilo}$ sank, nachdem am 1. März das Pankreas ganz exstirpirt worden war, am 16. März, als er keine Nahrung mehr erhielt, die Zuckerausscheidung auf Null und blieb so während 5 Tagen. Dass der Hund noch zuckerbildende Stoffe in sich hatte, ergibt sich daraus, dass er voin 21. bis 25. März bei Darreichung von Nutrose (Caseïnnatron) Zucker ausschied, obwohl doch sicher aus der Nutrose im Körper kein Zucker entstehen kann.

Versuch V. Nach Exstirpation des Pankreas sinkt bei Nahrungsentziehung die 48 stündige Zuckermenge von 44,6 a uf $22,8 \mathrm{~g}$ in $12 \mathrm{Tagen}$. Nutrose bedingt eine bedeutende Steigerung der Zuckerausscheidung.

Die Arbeit, welche von der Zuckerbildung aus Glycerin handelt, liefert folgende Reihen. 
Versuch I. Anfangsgewicht des Hundes 13,5 Kilo. Am 5. August Exstirpation des Pankreas. Der Hund erhält keine Nahrung. Die 24stündige Zuckerausscheidung sinkt von 17,4 g auf $\mathrm{Null}$ in 9 Tagen, bleibt auf Null 4 Tage, worauf in 5 Tagen wieder geringe $\mathrm{Zuckermengen}$ erscheinen, die in $24 \mathrm{Stunden} 0,3$ bis $1,25 \mathrm{~g}$ betragen.

Versuch II. Am 20. August war die Exstirpation des Pankreas, und schon nach 5 Tagen war das Thier todt. Hier war alsodurch die Operation eine schwere, nicht nothwendige Gefährdung des Thieres gesetzt. Dementsprechend bleibt die Zuckerausscheidung immer auf derselben Höhe.

Versuch III. Hier hat Lüthje keine tabellarische Uebersicht gegeben, obwohl der Hund dadurch interessant ist, dass er länger als 5 Wochen die Exstirpation des Pankreas überlebte, was die ausgezeichnete Operation der Chirurgen bezeugt. Der Hund erhielt keine Nahrung und wurde alsbald zuckerfrei und blieb so bis zum 35. Carenztage. Nähere Angaben fehlen.

Versuch IV. Von Prof. Küttner wird einem Hunde von 15,2 Kilo das Pankreas exstirpirt am 30. Januar. Das Thier lebte länger als bis zum 25. Februar; es ist nicht angegeben, wie lange. Hier haben wir es wieder mit einer ausgezeichnet ausgeführten Operation zu thun. In 4 Tagen sinkt nach der Exstirpation die Zuckerausscheidung von 16,0 g auf Null; dann werden Fütterungen nit Nutrose, Serum, Glycerin angeordnet, welche mächtige Zuckerausscheidungen veranlassen.

Ferner sind noch zwei ältere Versuche ${ }^{1}$ ) von Dr. Lüthje zu erwähnen, in denen er die Frage behandelt, ob nach Pankreasexstirpation die Zerstörung des Zuckers im Körper aufgehoben ist.

Versuch I. Ein Hund von $11 \mathrm{~kg}$, bei dem die Totalexstirpation des Pankreas von Prof. Küttner ausgeführt worden war, erhält rom 14. April ab kein Futter mehr. Am 15. April Exstirpation des Pankreas. Die mässige 24 stündige Zuckerausscheidung

1) Dr. Hugo Lüthje, Ist die Zerstörung des Zuckers nach Pankreasexstirpation vollständig aufgehoben? Münchner med. Wochenschr. Nr. 36. 8. Sept. 1903. 
sinkt, und am 27. April ist ier Harn zuckerfrei. Ein Aderlass am 28. April veranlasst am 29. April eine geringe Zuckerausscheidung $(0,7 \%)$. Am 1. und 2. Mai erhält der Hund Nutrose und scheidet an diesen beiden Tagen $8,5 \mathrm{~g}$ und $7,0 \mathrm{~g}$ Zueker aus. Am 4. Mai ist der Harn wieder zuckerfrei, und so blieb es bis zum 23. Mai, wo der Hund getödtet wurde. Die mikroskopische Untersuchung des Duodenums mit den benachbarten Peritonealblättern führte zu dem überraschenden Ergebniss, dass an einzelnen Stellen noch miliroskopische Reste gut erhaltenen Pankreasparenchyms vorhanden waren.

Desshalb wurde von Lüthje ein Versuch angestellt, bei dem nicht bloss das Pankreas, sondern auch das gesammte Duodenum herausgenommen worden ist, wodurch die vollkommene Entfernung des Pankreas gesichert war.

Versuch II. Am 11. August Totalexstirpation des Pankreas und Dünndarms. Bereits am 14. August ist kein Zucker mehr im Harn; so bleibt es bis zu dem am 17. August eintretenden Tod.

In den angeführten Versuchen macht sich die Thatsache geltend, dass die Zuckerausscheidung nach der Exstirpation beim Hungern des Thieres mehr oder weniger rasch abnimmt und dann vollkommen verschwindet. Diese Thatsache ist schon von anderen Forschern, wie z. B. Thiroloix, hervorgehoben, aber verschierlen erklärt worden.

Von hervorragender Bedeutung erscheint mir, dass diese zuckerfrei gewordenen Thiere sofort wieder Zucker in grossen Mengen ausscheiden, wenn sie mit Nahrungsstoffen gefüttert werden, welche, wie die Nutrose, ganz sicher nicht als Zuckerbildner betrachtet werden dürfen, wie ich oben bewiesen hahe. Ja, ein blosser Aderlass bedingt bei den zuckerfrei gewordenen Hunden das Wiedererscheinen des Zuckers im Harne auf kurze Zeit. Das pankreaslose Thier, das zuckerfrei gewordien ist, besitzt also Stoffe in sich, die grosse Massen von Zucker zu liefern vermögen, und trotzdem ist das Thier zuckerfrei. Daraus muss man schliessen, dass der Zuckergehalt des Blutes ein normaler ist. Lüthje untersuchte den Zuckergehalt des Aderlassblutes bei den beiden operirten Hunden, über welche in den beiden letzten Versuchen berichtet ist. Als sie zuckerfrei waren, fand er $0,203 \%, 0,097 \%$ in dem Blut des ersten Hundes; 0,312\% im Blut des zweiten Hundes. Genau sind diese Analysen nicht und bezeugen nur, dass reducirende Substanz vorhanden ist. Die Zucker- 
freiheit des Harnes bezeugt sicherer den normalen Zuckergehalt des Blutes. Da also hier ein Thier, das reichliche Zuckermengen aus sich zu liefern vermag, trotz des Verlustes des Pankreas keine Zuckerausscheidung zeigt, fehlt die Berechtigung, von dem Vorhandensein des Diabetes zu reden.

Wenn bei dem zuckerfreien Hunde im Blute Zucker vorkommt, so beweist dies nach $L$ üthje, dass auch nach der Totalexstirpation des Pankreas der Zuckerverbrauch im Körper nicht aufgehoben ist. Der in übergrosser Menge fortwährend gebildete Zucker wird also nach Lüthje so energiseh verbraucht, dass es, wie beim Gesunden, nicht zur Glykosurie kommt. Man kann sich aber auch vorstellen, dass im Blute desshalb Zucker ist, weil keiner verbraucht und keiner neugebildet wird, ebenso, dass wenig gebildet und wenig oxydirt wird. Man kann also aus dem Vorhandensein der gewöhnlichen Zuckerwerthe im Blute keinen Schluss anf den Zuckerstoffwechsel machen. Darin irrt Lüthje.

Thatsache ist: Beim Hungern wird der pankreaslose Hund zuckerfrei, obwohl er die Fähigkeit besitzt, noch Mengen von Zucker auszuscheiden.

Wenn auch der Hund vor der Totalexstirpation länger gehungert hat, tritt sofort nach der Operation die Glykosurie auf und verschwindet bei andauerndem Hunger wieder vollständig.

Diese Thatsachen machen den Eindruck, dass die totale Exstirpation des Pankreas als Reiz wirkt. Thiroloix ${ }^{1}$ ) hat ja früher den nach Ausrottung des Pankreas auftretenden Diabetes als traumatischen Diabetes gedeutet. Nur in den ersten Tagen, wo die Reizung der Abdominalhöhle in Folge der eingreifenden Verwundungen noch in voller Kraft besteht, beobachtet man einen stärkeren Diabetes, der bald abklingt, wenn man die Unterleibshöhle vor Erregung schützt. Jede Nahrungsaufnahme bedingt eine sofortige stärkere Blutfüllung, lebhafte Bewegungen der Gedärme, mit einem Worte erneute mächtige Reizung der vielen noch nicht vernarbten Wunden. Nun hat Lüthje in manchen Versuchen ganz ungeheure Nahrungsmassen den verwundeten Verdauungswerkzeugen übergeben. So erhält im Versuch 4 der Glycerinarbeit der Hund von 12,ð Kilo als Futter bis zu $1200 \mathrm{ccm}$ Serum + $360 \mathrm{ccm}$ Glycerin für 24 Stunden und entleert $6900^{\circ} \mathrm{ccm}$ Harn, d. h. mehr

1) J. Thiroloix, Compt. rend. t. 117 p. 342. 
als die Hälfte seines Körpergewichts. Das wäre so, als wenn ein Mensch von $60 \mathrm{Kilo}$ in 24 Stunden mehr als 30 Liter Harn ausschiede. Dass bei solcher riesigen Misshandlung der Verdauungswerkzeuge und der ganzen Abdominalhöhle die vorhandenen zahlzeichen Wunden auf's Neue heftigst gereizt werden, kann doch Niemand bezweifeln, und diese weit ausgebreitete Erregung der sensiblen Nerven genügt vielleicht, um auf reflectorischem Wege Diabetes hervorzurufen. Er wäre vielleicht auch erschienen, wenn Lüthje statt Glycerin oder Nutrosepulver Quarzpulver gefüttert hätte.

Die wichtige Thatsache, dass nach sorgfältigtser Entfernung des ganzen Pankreas kein Diabetes vorhanden ist, wenn man für Abhaltung der Wundreizung Sorge trägt, führt zur nothwendigen Folgerung, dass die Partialexstirpation des Pankreas desshalb einen nur geringen oder keinen Diabetes erzeugte, weil die Verletzungen eine geringere Ausdehnung hatten, also auch nicht so starke und umfangreiche Reizungen bedingten.

Nach der heutigen Auffassung übt das Pankreas einen specifischen Einfluss auf den Stoffwechsel der Kohlehydrate wesentlich durch Abgabe von Säften an das durchströmende Blut aus. Die Beweisführung liegt besonders in den von Minkowski erdachten Versuchen. Pankreasstücke werden unter die Haut des Thieres geheilt oder gepfropft. Nachdem ein Theil des Pankreas exstirpirt ist, wird der übrigbleibende Theil unter die Haut gelagert und hier eingeheilt. Damit uun dieses transplantirte Stück nicht abstirbt, muss es noch mit seinen Blutgefässen und Nerven, welche durch das Mesenterium zugeführt werden, in Verbindung bleiben, also durch einen dem Mesenterium angehörigen Strang mit der Bauchhöhle zusammenhängen. Wenn der Versuch gut gelingt, hat nun das Thier einen meist bald vorübergehenden oder auch keinen Diabetes. Sobald man glaubt, dass das unter die Haut gelagerte Stück mit dieser festgewachsen ist, durchschneidet man den Mesenterialstiel und entfernt das eingepflanzte Stück des Pankreas auch, worauf Diabetes eintritt. Nun kann man sagen, dass wegen der Durchschneidung des Mesenterialstieles die in denselben verlaufenden Mesenterialnerven, die vielleicht eine besondere reflectorische Beziehung zu den zuckerbildenden Organen haben, gereizt oder irgendwie beeinflusst werden, so dass hierdurch, nicht aber durch die Entfernung des Pankreasrestes der Diabetes bedingt wäre. 
Diesem Einwande ist durch Lancereaux und Thiroloix ${ }^{1}$ ) Rechnung getragen. Sie fanden in oft wiederholten Versuchen, dass das unter die Haut gepfropfte Pankreas den Diabetes verhindert, auch wenn es von seinen Nerven und Gefässen getrennt ist. Der Diabetes tritt ein, wenn das Stück Pankreas entfernt wird.

Da es nach den oben mitgetheilten Versuchen scheint, dass das Fehlen des ganzen Pankreas keineswegs nothwendig mit Diabetes verbunden ist, wird die bisherige Deutung des Transplantationsversuches zweifelhaft. Eine erneute Prüung ist nöthig. Es muss festgestellt werden, ob nach Einheilung des transplantirten Pankreasstückes die Durchschneidung des Mesenterialstieles ohne Entfernung des Pankreas nicht auch bereits Diabetes erzeugt.

Die Art, wie Lancereaux und Thiroloix vorgehen, scheint einwandfrei zu sein.

Sie vollziehen den Versuch in drei verschiedenen Zeiten, die durch viele Tage von einander getrennt sind.

In der ersten Operation wird die isolirte Pars duodenalis vom Pankreas nach Fröffnung der Bauchhöhle in das Unterhautzellgewebe eingenäht, so aber, dass die zugehörigen Blutgèfässe und Nerven erhalten hleiben. Das gepfropfte Pankreasstück hängt also noch durch einen Mesenterialstrang (pédicule vasculo-nerveux) mit dem Mesenterium der Bauchhöhle zusammen.

Zwei oder drei Wochen später wird der in der Bauchhöhle gelassene Rest des Pankreas vollständig entfernt und der Mesenterialstil, welcher aus der Bauchböhle zum eingeheilten Pankreasstück führt, durchschnitten. Dieses eingeheilte Stück bleibt und ergiesst einen Saft durch eine nach aussen führende Fistelöffnung. Das Thier wird nicht diabetisch.

In einer dritten Sitzung wird nun das eingeheilte Pankreasstück herausgeschnitten. Glykosurie und Azoturie erscheinen nach einigen Stunden. Wieviel Zeit verfliesst zwischen der zweiten und dritten Sitzung, sagen Lancereaux und Thiroloix nicht. Wenn der Versuch etwas beweisen soll, muss doch hier auch ein Zeitraum von mehreren Tagen vorausgesetzt werden. Auch ist die Angabe, dass nach der zweiten grossen Operation keine Glykosurie erscheint, wohl nicht so streng wörtlich gemeint. Denn E. Hédon ${ }^{2}$ ), der

1) E. Hédon, Compt. rend. t. 115 p. 292. - Lancereaux et Thiroloix, Compt. rend. t. 115 p. 341 u. p. 420. Maly's Jahresbericht f. 1895. Bd. 25 S. 535.

2) E. Hédon, Compt. rend. t. 115 p. 294. 
ebenso wie Lancereaux und Thiroloix diesen Versuch in 3 verschiedenen Zeiten ausführt und ebenso erst die Einheilung eines Pankreasstückes unter die Haut, dann zweitens die Entfernung des Pankreasrestes aus der Bauchböhle bewirkt, erklärt ausdrücklich, dass nach dem zweiten Act eine Glykosurie, die er gering nennt, auftritt, weil der Harn nur $4 \%$ Zucker enthält, was doch nicht wenig ist. Aehnliches wird auch von andern Forschern nach partieller Pankreasexstirpation gemeldet. Nach Hédon verschwindet diese "schwache" Glykosurie in wenigen Tagen. J. Thiroloix") berichtet übrigens in einer späteren Arbeit selbst, dass er nach der Exstirpation des Pankreasrestes aus der Bauchhöhle, also nach der zweiten Operation, eine "leichte" Glykosurie beobachtet habe, die er durch den Eingriff der Verwundung erklärt.

Wenn man die Deutung zulässt, welche den Pfropfungsversuchen Minkowski's besonders auf Grund der sinnreichen Anordnung von Lancereaux und Thiroloix gegeben worden ist, so bleibt ein Widerspruch übrig. Nach den oben mitgetheilten älteren und besonders neueren Pankreasexstirpationen, die von Dr. Eden und Prof. Küttner ausgeführt wurden, ergibt sich, dass die in einer Sitzung vollzogene Totalexstirpation des Pankreas häufig eine nur vorübergehende, schliesslich verschwindende Glykosurie erzeugt, während bei der in Intervallen ausgeführten Pankreasausrottung erst die letzte Operation, welche den unter die Haut geheilten Pankreasrest beseitigt, dauernde starke Glykosurie bedingen soll. Diese letzte Operation wird also an einem bereits sehr heruntergekommenen, dem Tode nahen Thiere ausgeführt.

Niemand anders als J. Thiroloix ${ }^{1}$ ) selbst bringt einen hochwichtigen Versuch, welcher heute die ernstesten Bedenken gegen die bisher beliebten Deutungen erregen muss.

Am 1. Juli 1892 wurde bei einem Hunde von $16 \mathrm{~kg}$ der duodenale Theil des Pankreas in gewohnter Weise unter die Haut gepfropft.

25 Tage später (26. Juli) wird das ganze Pankreas aus der Abdominalhöhle entfernt und der Mesenterialstiel, welcher das Peritoneum noch mit dem verlagerten Pankreasstück verknüpft, durchschnitten. Wäbrend der darauf folgenden 21 Tage ist der Hund abgeseben von einigen der Operation nachfolgenden Tagen - zuckerfrei. Das eingeheilte subcutane Pankreasstück secernirt in normaler 
Weise wie gewöhnlich durch das kleine Fistelloch der Haut. Alles ist bisher nach Wunsch und Erwarten verlaufen.

Da plötzlich am 18. August erscheint - noch vor Entfernong des eingeheilten Pancreasstückes - eine erst schwache, aber immer stïrker werdende Glykosurie, so dass der Hund am 29. August, also elf Tage nach dem Beginn der Glykosurie, bereits $50 \mathrm{~g}$ Zucker in 24 Stunden ausscheidet. Es treten dann alle Erscheinungen des Diabetes hervor: neben der starken Glykosurie, Azoturie, Polyurie, Polyphagie, Abmagerung (4. September).

Es wurde genau untersucht, ob etwa das eingeheilte Stück Pankreas abgestorben sei. Daran war nicht zu denken. Denn das Pankreasstück hatte fortgefahren, reichlich zu secerniren. Man konnte aus der Hauttasche täglich 15 bis $20 \mathrm{cem}$ eines kJaren, durchsichtigen und wie normaler Bauchspeichel reagirenden Saftes entnehmen. Die Untersuchung des eingeheilten Pankreasstückes zeigte, dass es wohl erhalten war. Nun meint Thiroloix, man müsse annehmen, dass trotzdem die innere Secretion aufgehoben war, welche sonst den Kohlehydratstoffwechsel beherrscht.

Man kann dies gewiss annehmen, aber die Thatsache, dass die in einer Sitzung vollzogene Ausrottung des Pankreas nicht nothwendig Diabetes erzeugt, ist damit nicht aus der Welt geschafft. Man könnte einwenden, dass diese Fälle ihre Erklärung fänden, weil das Pankreas nicht vollständig entfernt war. Dagegen spricht, dass auch bei Exstirpation des Pankreas mit dem Dünndarm kein Diabetes einzutreten braucht, obwohl in diesem Falle die Vollständigkeit der Ausrottung ganz gesichert ist. Es ist das der Versuch, den Professor $\mathrm{K} u \mathrm{ttne} \mathbf{r}$ angestellt und über den $\mathrm{H}$. Lüthje, wie oben bereits genauer dargelegt, berichtet hat. -

Der Einwand der unvollständigen Ausrottung des Pankreas wird ausserdem dadurch hinfällig, dass so viele Beobachter die Transplantationsversuche Minkowski's bestätigt haben. Das setzt aber voraus, dass das Pankreas vollständig aus der Abdominalböhle entfernt worden ist, oder doch, dass mikroskopische Reste nicht in Betracht kommen. Die totale Exstirpation muss also doch nicht gar so schwierig sein.

Nun sind die von Lüthje beschriebenen Versuche von zwei offenbar ausgezeichmeten Chirurgen gemacht, wie aus der langen Lebenstauer der operirten Thiere hervorgeht. 
Wir wollen nun also fragen, $o b$ es nicht vielleicht noch eine andere als die bisherige Deutung des Pankreasdiabetes gibt.

Der Beweis von Lanceraux und Thiroloix liegt darin, dass das unter die Haut eingeheilte Pankreasstück die Entstehung des Diabetes auch dann noch verhindert, wenn es nicht mehr durch seine Blutgefässe nnd Nerven mit dem Mesenterialstiele und dem Peritoneum zusammenhängt. Man ist zuerst geneigt, zuzugeben, dass dieser Bedingung genügt wurde dadurch, dass die beiden Forscher den Mesenterialstiel lange vor der Entfernung des eingeheilten Pankreasstückes durchschnitten. Ist dies nun wirklich zweifellos, dass die Beziehung des eingeheilten Drüsenstückes zu den Nerven der Bauchhöble desshalb aufgehoben ist? Ich sage: das ist nicht zweifellos. Warum?

Ungefähr drei Wochen verfliessen, nachdem der Duodenaltheil des Pankreas unter die Haut gepfropft worden ist. In dieser Zeit haben sich neue Blutgefässe gebildet, welche aus der Haut in das Parenchym der Drüse eindringen. Das Gefässnetz der Haut communicirt mit dem Gefässnetz der Drüse. So erzählt E. H è don ${ }^{1}$ ), dass man nach Ausbildung dieser Gefässcommunication den Mesenterialstiel unterbinden kann, ohne das Leben des eingeheilten Drüsenstückes zu sehädigen. Nun ist es klar, dass nicht bloss das Drüsenstück, sondern auch sein Stiel, der nach dem Peritoneum führt, ebenso durch Blutgefässnetze mit dem benachbarten Bindegewebe der Haut in Verbindung getreten sein wird. - Mit den verbindenden Blutgefässnetzen entstehen unzweifelhaft auch neu die zugehörigen Nervennetze. Trotz der Durchschneidung des Mesenterialstieles können also nervöse Erregungen aus dem Drüsenstück durch die collateralen Bahnen der neuen Nervennetze nach denen der $\mathrm{Ab}$ dominalhöhle gelangen. Es ist also nicht sicher, dass das unter der Haut eingeheilte Pankreastück durch Blutgefässe und Nerven mit dem Peritoneum der Bauchhöhle nicht mehr in functioneller Verbindung steht. Die Wegnahme des Pankreaspfropfes wirkt also vielleicht doch durch die mit der Nervendurchschneidung bedingte Erregung der nach dem Abdomen ziehenden Nerven.

Die wichtige Frage ist: Wie kommt es, dass die in einer Sitzung in kunstgerechter Weise vollzogene totale Exstirpation des Pankreas keinen Diabetes erzengt, während die in verschiedenen,

1) E. Hédon, Compt. rend. t. 115 p. 298. 
durch lange Zeiträume getrennten Sitzungen vollzogene Operation Diabetes bedingt?

Zuerst möchte ich hervorheben, dass ein Hund, der sich in mangelhaftem Ernährungszustande befindet, schon ohne Exstirpation des Pankreas an Diabetes erkrankt. Das ist der sogenannte Hungerdiabetes von Hoffmeister ${ }^{1}$ ). Dieser Forscher fand, dass ein Hund durch Nahrungsentziehung diabetisch gemacht werden kann. Er scheidet nach mässigen Gaben Stärke Zucker aus bis zu $30 \%$ der eingeführten Stärke.

Dieser Versuch ist hochwichtig, aber von unserem Standpunkt aus nicht schwer zu verstehen. Der Hunger hat zur Folge, dass der grösste Theil des Stoffwechsels durch Fett und Kohlehydrat bestritten wird. Da aber, wie wir jetzt annehmen, das Fett nur oxydirt werden kann, nachdem es sich in Zucker verwandelt hat, foly $\tau$, dass der ganze Stoffwechsel fast nur durch Oxydation von Zucker bestritten wird. Es müssen demnach die Zellen, welche die Verarbeitung des Zuckers durch Oxydation zu bewirken haben, auf das Aeusserste angestrengt sein, so dass eine Erschöpfung und veränderte Leistungsfähigkeit derselben begreiflich erscheint. Das heisst mit anderen Worten, dass die Zuckermenge, welche zur Befriedigung aller Bedürfnisse oxydirt werden sollte, nicht mehr ganz bewältigt werden kann. Es tritt dann Zucker in das Harn über.

Weil aber das Fett, um vollständig oxydirt werden zu können, zuerst in Zucker durch besondere Zellarbeit übergeführt werden muss, fühı t auch diese auf das Höchste gesteigerte Arbeit zur Erschöpfung, so dass die Nachlieferung der zur Oxydation nötbigen Zuckermenge geschädigt ist.

Weil die stickstofffreien Substanzen trotz höchster Anspannung aller Kräfte also doch nicht mehr genügen, muss das Eiweiss, d. h. die lebendige Zellsubstanz, selbst geopfert oder oxydirt werden. Da sie es aber ist, welche den Zucker zur Oxydation verarbeitet, so ist es klar, dass auch hier eine Schwächung der Leistung nothwendig eintreten muss aus zwei Gründen: wegen abnehmender Arbeitskrait der ermüdeten Zellsubstanz und wegen Verringerung ihrer leistungsfähigen Masse.

Ist das Thier durch Hunger einmal bis zu diesem herabgekommenen Zustande gelangt, so genügt natürlich. eine kleine

1) Naunyn, Diabetes mellitus S. 37 . 
Steigerung der für die Oxydation des Zuckers nöthigen Arbeit durch Zufuhr von wenig Zucker in der Nahrung -, um durch Uebergang desselben in den Harn zu bezeugen, dass er nicht mehr oxydirt werden konnte. Wie man sieht, genügt ein stark heruntergekommener Ernährungszustand eines Thieres, um Diabetes oder doch eine dem Diabetes angenäherte Form der Stoffwechselstörung durch geringfügige Veranlassungen hervorzubringen. Es ist hierzu. keine Exstirpation des Pankreas nöthig.

Wie steht es nun mit einem Thier, dem das Pankreas ganz oder partiell exstipirt wurde, vorausgesetzt zuerst, dass es keine Nahrung erhält? Es ist klar, dass sich der durch die Wundreizung gesetzte traumatische Diabetes addirt zu dem dureh den Hunger bereits vorhandenen. Solange das Thier noch bei gutem Ernährungszustande ist, gelingt es ihm, sobald nach einigen Tagen die Wundreizung nachgelassen hat, die reflectorisch erregten grossen Zuckermengen so weit zu oxydiren, dass kein Zucker mehr in den Harn übertritt. Je länger aber dieser Zustand dauert, desto eher muss der Hungerdiabetes in verstärktem Maasse sich geltend machen. Thiroloix beobachtete ja sein Eintreten erst einige Wochen nach partieller Exstirpation des Pankreas. Wenn also nach vor längerer Zeit ausgeführter partieller Exstirpation an dem bereits stark herabgekommenen Thier ein neuer Eingriff gemacht wird, so genügt dieser vielleicht, um den Diabetes deutlich hervortreten zu lassen.

Wie steht es nun, wenn ein Thier nicht hungert, sondern nach Exstirpation des Pankreas gefüttert wird? Die dann eintretende Verdauung und Resorption bedingt eine erhöhte Blutfülle, Steigerung der Arbeit aller Zellen der Verdauungswerkzeuge, vor Allem stärkere peristaltische Bewegungen. Das sind alles Bedingungen, welche die zahlreichen in der Bauchböhle vorhandenen Wunden auf das Heftigste reizen und durch Reflex die Zuckerbildung steigern. Der mit der Nahrungszufuhr verbundene Vortheil wird so compensirt. - Auf der anderen Seite ist zu bedenken, dass bei Wegfall des Pankreas die Verdauungsprocesse erheblich geschädigt sind. Die Fette, denen ein so hoher Kraftwerth innewohnt, gehen zum grossen Teil durch den Koth verloren.

Ich hatte Gelegenheit, die Faeces eines Mannes zu untersuchen, der nach der durch Professor Jores ausgeführten Section an secundärem Pankreas-Carcinom litt. Der Koth schwamm auf dem Wasser. Die festen Bestandtheile waren zur Hälfte in Aether lös- 
lich und bestanden zu ungefähr gleichen Theilen aus fetten Säuren und Neutralfett. Im Harn war niemals Zucker nachzuweisen. Auch die physiologischen Thierversuche bezeugen, dass nach Wegfall des Bauchspeichels die Resorption der Fette auf das Tiefste geschädigt ist.

Da das Pankreas sehr stark bei der Verdauung der Kohlehydrate und nach allgemeiner Ansicht doch auch der Eiweisstoffe betheiligt ist, so liegt es auf der Hand, dass ein Thier, dem das Pankreas genommen ist, nach mehreren Wochen in einem Zustand starken Verfalles sich befinden muss. Es werden für die Oxydation des Zuckers die höchsten Ansprüche gemacht, und die den Zucker verarbeitenden Organe sind durch Ueberanstrengung erschöpft.

Ich wollte durch diese Erörterungen nur gezeigt haben, dass die Ursache des Pankreasdiabetes keineswegs mit Sicherheit aufgeklärt ist, sondern erneuter Arbeit bedarf. Vor allen Dingen muss festgestellt werden:

1. Totale Exstirpation des Pankreas, welche in einer Sitzung an einem in bestem Ernährungszustande befindlichen Thiere von der geübten Hand eines guten Chirurgen in schonendster Weise ausgeführt wird, hat wirklich keinen Diabetes zur Folge.

2. In beweisender Form ausgefuhrte Wiederholung des Seegen'schen, von J. Weiss ${ }^{1}$ ) bestätigten Versuches: Zuckerbildung durch Digestion von Leberbrei mit Fett und Fettsäuren.

3. Herstellung solcher Bedingungen bei diabetischen Hunden, dass die grossen ausgeschiedenen Zuckermengen aus präformirtem Kohlehydrat nicht ableitbar sind.

1) J. Weiss. Ueber die Bildung von Zucker aus Fett im Thierkörper. Zeitschr. f. physiolog. Chemie Bd. 24 S. 542. 1898. 
Arch. f d. ges. Physiol. Bd. 103.

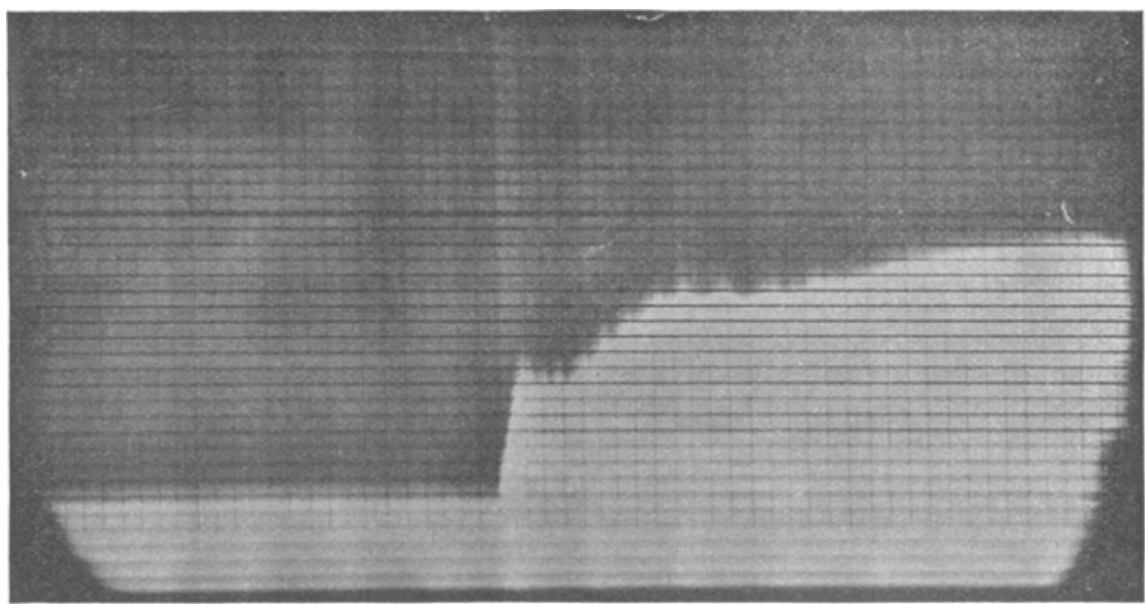

Fig. 1

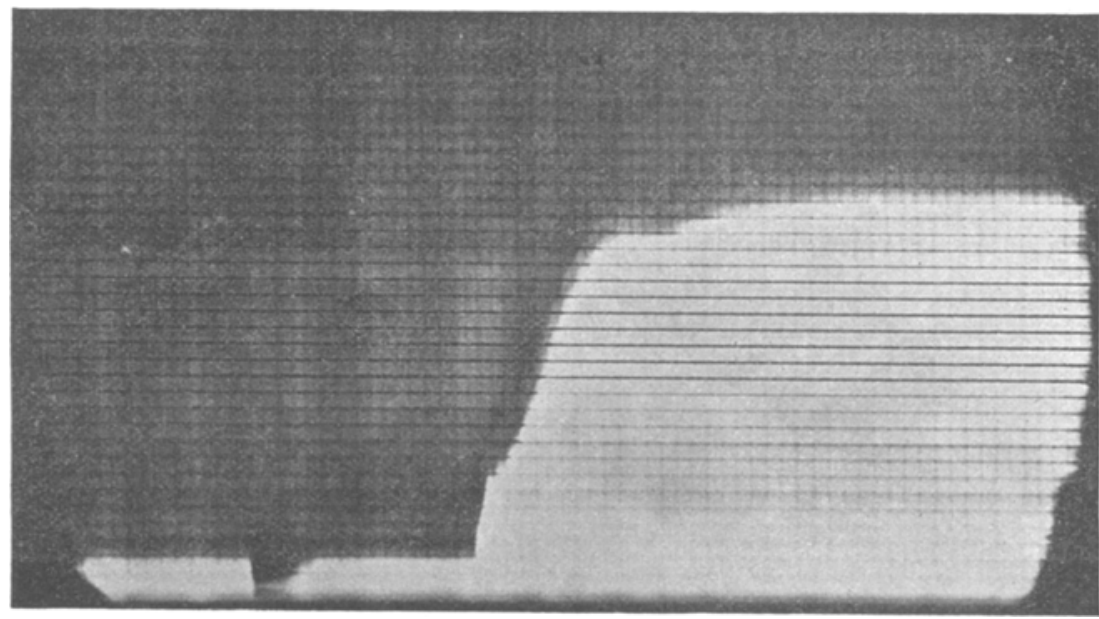

Fig. 2.

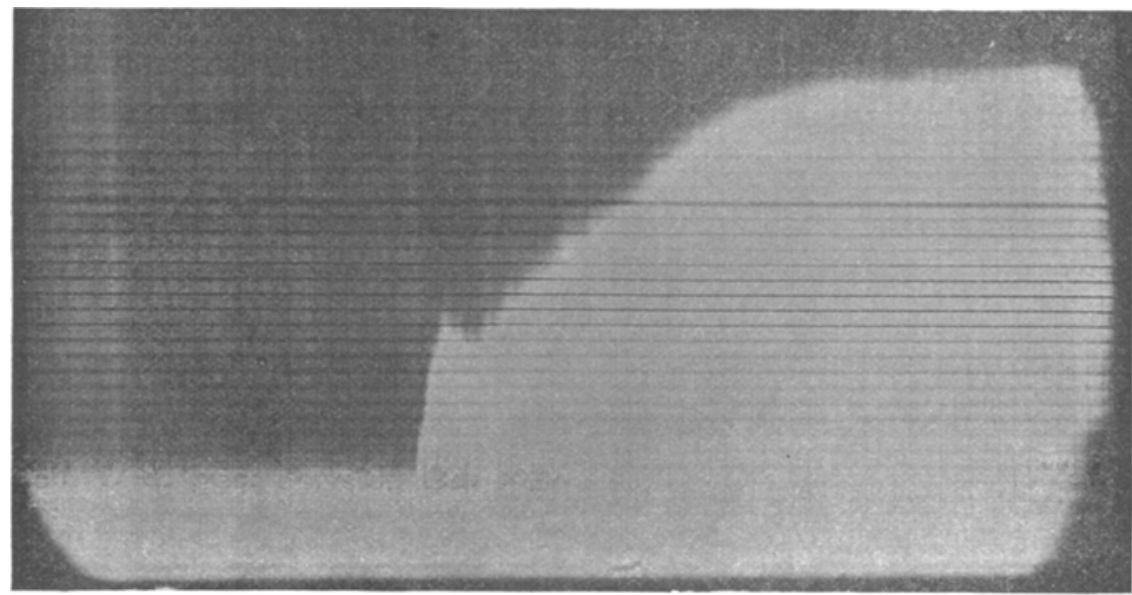

Fig. 3. 


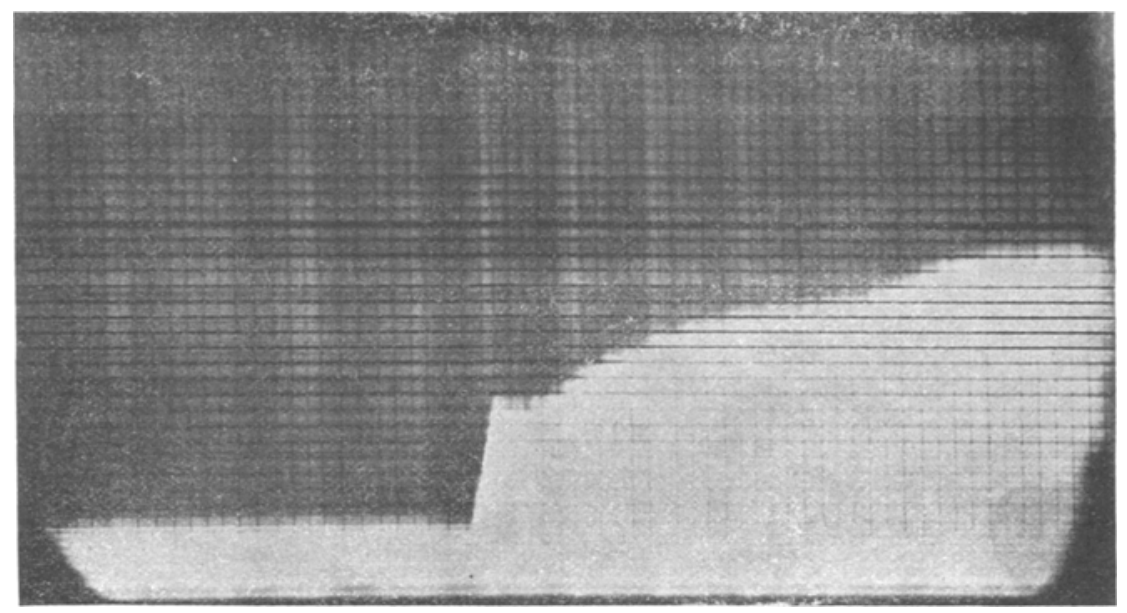

Fig. 4.

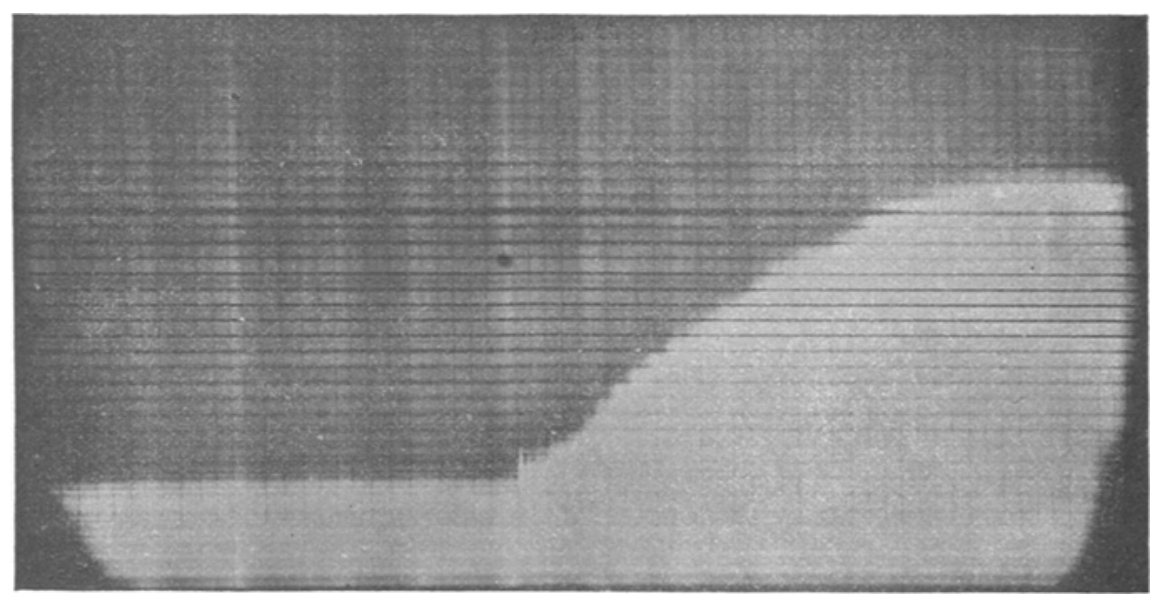

Fiy

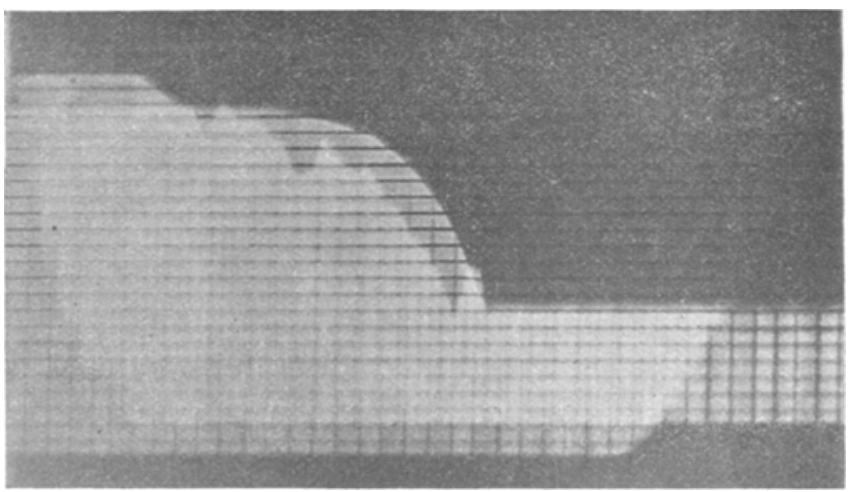

Fig. 6. 